\title{
CFD study on thermal transport in open-cell metal foams with and without a washcoat: Effective thermal conductivity and gas-solid interfacial heat transfer
}

\author{
Wenping Peng ${ }^{1,2}$, Min $\mathrm{Xu}^{1 *}$, Xunfeng $\mathrm{Li}^{1}$, Xiulan Huai ${ }^{1 *}$, Zhigang $\mathrm{Liu}^{3}$, Huasheng Wang ${ }^{4}$, \\ 1. Institute of Engineering Thermophysics, Chinese Academy of Sciences, Beijing 100190, China \\ 2. University of Chinese Academy of Sciences, Beijing 100049, China \\ 3. Energy Research Institute of Shandong Academy of Sciences, Jinan 250014, China \\ 4. School of Engineering and Material Science, Queen Mary University of London \\ *Corresponding authors. Tel/Fax.: +86-10-82543108; \\ *E-mail address: xumin@iet.cn, hxl@iet.cn;
}

\begin{abstract}
The metal foams are considered as the attractive catalyst carriers for strongly exo-/endo-thermic catalytic processes, but the washcoat may have a significant influence on the thermal transport properties of metal foams. In this study, effective thermal conductivity and gas-solid interface heat transfer of coated metal foams were studied using a periodic unit cell model by the CFD method. We gave special emphasis to analyze the effect of the washcoat on effective thermal conductivity, pressure drop and interface heat transfer of metal foams. The results indicated that the influence of the washcoat on effective thermal conductivity depends on the conductivity of three phases. The great deviat ion was found when we used the available empirical correlations for metal foams to predict the effective thermal conductivity of coated metal foams under the same porosity. A correlation of effective thermal conductivity suitable for coated metal foams was proposed by considering the washcoat as a separate phase. In addition, pressure drop increases with the increase of the washcoat thickness whereas gas-solid interface heat transfer decreases with it. Moreover, we verified the enhancement of viscous flow within the washcoat on the interface heat transfer for coated metal foams. The simulated results revealed that a maximum increase in Nusselt number by the factor of about 13 was obtained in turbulent flow if the viscous flow within the washcoat was accounted for. The present study may provide a guideline to the structured catalyst and reactor designs for strongly exo-/endo-thermic catalytic processes.
\end{abstract}

Keyword: Catalytic reactor, Metal foams, Washcoat, Thermal transport property, Process intensification

\section{Introduction}

High porosity open-cell metal foams recently have seen more and more applications because of their high porosity, high thermal conductivity, large flow mixing, high surface area and good mechanical properties (Zhao, 2012). Considering so many advantages, the metal foams have also been used to be catalyst supports for strongly exo-/endo-ther mic catalytic processes in fixed-bed reactors, such as steam reforming of hydrocarbons (Richardson and Hung, 2003a), 
oxidation or partial oxidation of hydrocarbons (Williams and Schmidt, 2006), waste and exhaust gas purification (Fino et al., 2005), preferential oxidation of carbon monoxide (Chin et al., 2006) and so on.

It has been observed that the overall performance of the reactors with metal foams as catalyst supports, such as activity, selectivity and stability, can be significantly improved compared to the reactors packed by the traditionally used catalyst pellets. For example, De Wild and Verhaak (2000) had compared the performance of steam reforming in coated aluminum foams and commercial pellets packing. The results showed that the coated aluminum foams have lower conversion temperature and long-term stability for steam reforming. Giani et al. (2005) made an evaluation on the performance of foams, packed beds and honeycomb monoliths as catalyst supports on the basis of a dimensionless merit index which accounted for the tradeoff between pressure drop and mass transfer property. It was concluded that foams are largely superior to packed beds because of their high porosity, but perform slightly worse than honeycomb monoliths. However, compared to honeycomb monoliths, foams can afford remarkable reductions of reactor volume and weight in diffusion-controlled processes where pressure drop is of minor concern. Yu et al. (2010) also investigated the technology for continuous and high-efficiency alkali-catalyzed biodiesel synthesis. Compared to the conventional stirred reactors, the metal foam reactors significantly reduce energy consumption and shorten reaction period. The excellent performance of the metal foam reactors mentioned above is mainly due to the fact that metal foams have a high heat and mass transfer efficiency, such as high thermal conductivity (Coquard et al., 2012; Mendes et al., 2014; Zhao et al., 2004), high heat dissipation (Bianchi et al., 2012; Dietrich et al., 2011; Peng and Richardson, 2004; Zhao et al., 2005; Hetsroni et al., 2008; Zhao et al., 2010), outstanding interface heat and mass transfer (Calmidi and Mahajan, 2000; Younis and Viskanta, 1993; Giani et al., 2005) and good wall heat transfer (Bianchi et al., 2013; Bianchi et al., 2015). Excellent heat and mass transport properties of metal foams contribute to a great enhancement on the synergy characteristic between heat and mass transports and chemical reaction to improve the efficiency of the catalytic reactors.

The interface mass transport property of coated metal foams has been studied in some previous researches (Giani et al., 2005; Groppi et al., 2007; Garrido et al., 2008). For example, Giani et al. (2005) measured the gas-solid mass transfer coefficient of metal foams with a $\mathrm{Pd} / \mathrm{Al}_{2} \mathrm{O}_{3}$ catalytic washcoat by means of $\mathrm{CO}$ combustion tests. A dimensionless correlation of the mass transfer coefficient was obtained with the average diameter of the foam struts as the characteristic length. Later, Groppi et al. (2007) extended this correlation (Giani et al., 2005) to ceramic foams with higher relative density by means of $\mathrm{CO}$ combustion tests in the diffusion-limited regime over $\mathrm{Pd} / \gamma-\mathrm{Al}_{2} \mathrm{O}_{3}$ coated foams. Garrido et al. (2008) also made a measurement on the gas-solid mass transfer coefficient of the coated foams by monitoring the CO oxidation over $\mathrm{Pt} / \mathrm{SnO}_{2}$ coated foams in the temperature regime where external mass transfer is rate determining. A unifying description of the dimensionless mass transfer coefficient was there proposed by introducing an additional geometrical factor. However, a detailed analysis on the thermal transport properties of coated metal foams is lack at 
present. The thermal transport properties of metal foams may be unable to directly extend to those with washcoat.

In fact, there is no doubt that the washcoat has a significant influence on the thermal transport properties of metal foams, such as effective thermal conductivity, gas-solid interface heat transfer and radiation heat transfer: (i) The washcoat could greatly affect the effective thermal conductivity of metal foams. One reason is that the washcoat may have a thermal conductivity very different from metal foams and gas-phase reactants or products. For example, the conductivity of the $\alpha-\mathrm{Al}_{2} \mathrm{O}_{3}$ and SBA-15 washcoats is about $10 \mathrm{~W} / \mathrm{m} / \mathrm{K}$ and $0.3 \mathrm{~W} / \mathrm{m} / \mathrm{K}$ (Huang et al., 2013) respectively, having a great difference compared to copper and aluminum foams. Another reason is that the washcoat may make the structural properties of metal foams changed, such as fraction of solid material in struts and lumps. Mendes et al. (2013) had made a conclusion that the effect of fraction of solid phase between struts and lumps on the effective thermal conductivity is about one order of magnitude. (ii) The washcoat has an influence on cell size, porosity and surface area of metal foams, consequently affecting the gas-solid interface heat transfer characteristic as well as pressure drop (Paek et al., 2000; Fourie and Du Plessis, 2002; Inayat et al., 2016). In addition, some cracks and cavities may exist within the washcoat, depending on the actual coating procedure (Zhang et al., 2002; Novak et al., 2013). Novak et al. (2013) had investigated the contribution of cracks and cavities to diffusion in catalytic washcoat and the result showed that the presence of cracks and cavities can make the overall effective diffusivity 1.7 times higher in absence of these structural defects. Liu et al. (2005) verified the great enhancement of the interface mass transfer by the factor of about 2.5 in monolith reactors for laminar flow when the viscous flow presents within the macro-pore catalyst layer. It was concluded that an enhanced mass transfer is due to a decrease in external film resistance. Therefore, the washcoat undoubtedly has a great influence on the gas-solid interface heat transfer. (iii) The radiation heat transfer also varies with the change of structural and optical parameters caused by the washcoat. Zhao et al. (2004) had pointed out that the radiation heat transfer increases rapidly with temperature increased, particularly in the higher temperature range (500-800K). The radiation heat transfer increases with increasing pore size or decreasing porosity (Zhao et al., 2004; Mendes et al., 2014; Dietrich et al., 2014).

The present study aims to: (i) achieve 3D CFD simulations on effective thermal conductivity and gas-solid interface heat transfer of coated metal foams using a periodic unit cell model; (ii) analyze the influence of the washcoat on effective thermal conductivity and propose a correlation of effective thermal conductivity suitable for coated metal foams; (iii) make a analysis on the influence of the washcoat on the flow and gas-solid interface heat transfer; and (iv) verify the enhancement of viscous flow in washcoat on the gas-solid interface heat transfer of coated metal foams.

\section{Geometrical model}

A microscopic approach is in this work used to study the thermal transport properties of coated metal foams for 
catalytic reactors. The body-centered-cubic structure proposed by Krishnan et al. (2006), as shown in Fig. 1a), is chosen for metal foams in view of its similarity to the Kelvin's tetrakaidecahedron structure and convenience for coating. It is not repeated for the building of the body-centered-cubic foam structure and one could refer to the literature of Krishnan et al. (2006). The following conditions must be satisfied for the building of the body-centered-cubic foam structure:

$$
R>a ; \quad \arcsin \frac{a}{s}>\arccos \frac{s}{2 R}
$$

where $R$ is the cell radius, namely $d_{\mathrm{c}} / 2, a$ is half of the unit cell length, namely $L / 2$ and $s$ is the distance between the center of unit cell and its vertexes.

The mean pore diameter is approximated by:

$$
d_{\mathrm{p}}=2 \sqrt{R^{2}-(s / 2)^{2}}
$$

The mean strut diameter is approximated by:

$$
d_{\mathrm{s}}=\sqrt{2} a-R-\sqrt{R^{2}-a^{2}}
$$

One important defect of the body-centered-cubic foam structure is that it ceases to be open for the case of porosity below 0.94 , deviating from the real metal foams in morphology (Krishnan et al., 2006). Therefore, we choose three metal foam models with the porosity of $0.9522,0.9754$ and 0.9908 to be coated, corresponding to the parameter $L / d_{\mathrm{c}}$ of 0.99 , 0.97 and 0.95 respectively. The cell diameter of metal foams is fixed to be $2.54 \mathrm{~mm}$, considering that dimensions have no direct effect on effective thermal conductivity except of the morphology, in absence of convection and radiation. The washcoat is coated on the surface of the body-centered-cubic foam structure by the method as follows: (i) Create nine concentric spherical annuluses with the outer diameter of $d_{\mathrm{c}}$ and the inner diameter of $d_{\mathrm{c}}-2 t_{\mathrm{w}}$ using the center and eight vertices of the unit cell cube respectively as the annulus center. (ii) Subtract those eight spherical annuluses with the annulus center at the vertices by the unit cell cube and cut the part blocking the pores of the body-centered-cubic structure. (iii) Connect all the concentric spherical annuluses to form the geometric structure of the washcoat. Fig. 1b) shows the coated metal foam model and the thickness of the washcoat could be adjustable within $100 \mu \mathrm{m}$. The unit cell of coated metal foams is composed of metal support zone, washcoat zone and fluid zone with different morphology and volume fraction, as shown in Fig. 1c). The volume fraction of these three zones in the coated metal foam model can be estimated as follows:

The unit cell cube has the volume of:

$$
V=L^{3}
$$

The volume of washcoat zone is estimated using the following expression: 


$$
\begin{aligned}
V_{\mathrm{w}}= & 2\left[\frac{4}{3} \pi R^{3}-\frac{4}{3} \pi r^{3}-6 \pi\left(R^{2}-a^{2}\right)\left(\frac{R}{a}\right)^{2}(R-r)-8 \pi\left(R^{2}-\frac{s^{2}}{4}\right) \frac{(\sqrt{6} / 2 \cdot a)^{2}+(R-\sqrt{3} / 2 \cdot a)^{2}}{(3 / 2) a}(R-r)\right] \\
& 12(R-r)^{2} \cdot 2 \pi \sqrt{R^{2}-a^{2}}+8(R-r)^{2} \cdot 2 \pi \sqrt{R^{2}-(s / 2)^{2}}
\end{aligned}
$$

The volume of fluid zone is derived as:

$$
V_{\mathrm{f}}=2\left[\frac{4}{3} \pi R^{3}-8 \pi\left(\frac{2}{3} R^{3}-\frac{s}{2} R^{2}+\frac{1}{3}\left(\frac{s}{2}\right)^{2}\right)-6 \pi\left(\frac{2}{3} R^{3}-R^{2} a+\frac{a^{3}}{3}\right)\right]-V_{\mathrm{w}}
$$

The volume of support zone is obtained by subtracting the volume of washcoat and fluid zones from the unit cell volume:

$$
V_{s}=V-V_{\mathrm{w}}-V_{\mathrm{f}}
$$

Finally, the volume fraction of support zone, washcoat zone and fluid zone is estimated by the following expressions:

$$
\varepsilon_{\mathrm{s}}=\frac{V_{\mathrm{s}}}{V}, \varepsilon_{\mathrm{w}}=\frac{V_{\mathrm{w}}}{V}, \varepsilon_{\mathrm{f}}=\frac{V_{\mathrm{f}}}{V}
$$

The volume fraction of these three zones for the structures studied can be calculated by Eqs. (4-8) and the structural parameters are summarized in Table 1 . To validate the reliability of the proposed coated metal foam model in structural properties, the specific surface areas of the model are compared with the predicted ones by the correlation of Inayat et al. (2011) for the triangular concave strut which has been widely verified, as shown in Fig. 2. It can be seen that the specific surface areas calculated by our model are in agreement with the predicted values by the correlation for the triangular concave strut. To some extent, the coated metal foam model is able to represent the structural properties of the real situation.

\section{Effective thermal conductivity}

The metal foams without washcoat contain two distinct phases, a solid phase and a fluid phase, with different conductivities of $k_{\mathrm{s}}$ and $k_{\mathrm{f}}$. However, a micro-nano porous medium is introduced for coated metal foams in addition to solid and fluid phases. This micro-nano porous washcoat has a distinctly different thermal conductivity $k_{\mathrm{w}}$ from the solid phase and fluid phase. It is therefore essential for us to obtain the effective thermal conductivity of metal foams with and without washcoat and analyze the effect of washcoat on the effective thermal conductivity.

\subsection{Governing equations and boundary conditions}

The 3D steady-state heat conduction equation describes the heat transfer due to pure conductivity in coated metal foams and its expression in Cartesian coordinates is given as follows: 


$$
\frac{\partial}{\partial x_{i}}\left(k \frac{\partial T}{\partial x_{i}}\right)=0
$$

where the thermal conductivity $k$ depends on local material or phase.

A specific temperature difference $T_{\mathrm{h}}-T_{\mathrm{c}}\left(T_{\mathrm{h}}>T_{\mathrm{c}}\right)$ is introduced in the $z$ direction to the computation domain and the remaining four boundaries are set to be adiabatic in order to ensure one-dimensional heat transport:

$$
\left.T\right|_{z=0}=T_{\mathrm{h}} ;\left.T\right|_{z=L}=T_{\mathrm{c}} ;\left.\frac{\partial T}{\partial x}\right|_{x=0, L}=0 ;\left.\frac{\partial T}{\partial y}\right|_{y=0, L}=0
$$

\subsection{Numerical methodology}

Fig. 3a) shows the computation domain for the simulations on effective thermal conductivity of coated metal foams, composed of metal support zone, washcoat zone and fluid zone. Tetrahedral grid is chosen to mesh these three zones by the software ANSYS Icem, as shown in Fig. 3b). 3D steady-state heat conduction equation (Eq. (9)) is applied to the computation domain of the unit cell after the mesh file is imported into the software ANSYS Fluent. The diffusive term in heat conduction equation is discretized by the second-order central scheme. The boundary conditions described in Eq. (10) are added in the computation domain. $T_{\mathrm{h}}$ in high temperature side is set as $400 \mathrm{~K}$ and $T_{\mathrm{c}}$ in low temperature side is $300 \mathrm{~K}$. Coupled condition is used for the support-washcoat interface and the washcoat-fluid interface. The materials chosen for three phases and physical property parameters are summarized in Table 2. The simulations are not terminated until the residual for the heat conduction equation falls below $1 \times 10^{-9}$. The average temperature at the support-washcoat interface and the washcoat-fluid interface is also defined to monitor the convergence of the numerical calculations. As an example, the monitor of a case with parameters of $L=0.95 d_{\mathrm{c}}$ and $t_{\mathrm{w}}=100 \mu \mathrm{m}$ is shown in Fig. $3 \mathrm{c}$ ). Moreover, mesh independence of the solution for mesh number used in simulations is tested. Five sets of meshes with total element number respectively of $425511,608509,955670,1661500$ and 3209396 are used for the test and the predicted effective thermal conductivity for these mesh systems is shown in Fig. 3d). It indicates that the effective thermal conductivity nearly remains constant when the mesh number exceeds 1661500 corresponding to the maximum mesh size of $d_{\mathrm{c}} / 50$. Therefore, a maximum mesh size $d_{\mathrm{c}} / 50$ is chosen for all the cases studied to find a balance point between the calculating accuracy and the required time.

The average steady-state heat flux is obtained using the following expression from the simulated temperature field:

$$
q=\frac{1}{2 A}\left(\left.\iint k \frac{\partial T}{\partial z}\right|_{z=0} d x d y+\left.\iint k \frac{\partial T}{\partial z}\right|_{z=L} d x d y\right)
$$

where, $A$ is the area of heat flux.

The effective thermal conductivity is derived using the averaged Fouriers law: 


$$
k_{\mathrm{e}}=\frac{q L}{T_{\mathrm{h}}-T_{\mathrm{c}}}
$$

\section{Gas-solid interface heat transfer without viscous flow in washcoat}

\subsection{Governing equations and boundary conditions}

No viscous flow exists in micro-nano porous washcoat due to its small pore size in nanometer level. The flow and interface heat transfer of coated metal foams could be described by the 3D steaty-state mass, momentum and energy conservation equations for the incompressible Newtonian fluid in fluid zone.

The continuity equation is given as:

$$
\frac{\partial}{\partial x_{\mathrm{i}}}\left(\rho_{\mathrm{f}} u_{\mathrm{i}}\right)=0
$$

where $\rho$ is the mass density, $x_{i}$ is the Cartesian coordinates and $u_{i}$ is the velocity components.

The momentum equation is given as:

$$
\frac{\partial}{\partial x_{\mathrm{j}}}\left(\rho_{\mathrm{f}} u_{\mathrm{i}} u_{\mathrm{j}}\right)=-\frac{\partial p}{\partial x_{\mathrm{i}}}+\frac{\partial \tau_{\mathrm{ij}}}{\partial x_{\mathrm{j}}}+\rho_{\mathrm{f}} g_{\mathrm{i}}
$$

where $p$ is the static pressure, $g_{\mathrm{i}}$ is the gravitational body force and $\tau_{\mathrm{ij}}$ is the stress tensor, defined as follows for Newtonian fluid:

$$
\tau_{\mathrm{ij}}=\left[\mu_{\mathrm{f}}\left(\frac{\partial u_{\mathrm{i}}}{\partial x_{\mathrm{j}}}+\frac{\partial u_{\mathrm{j}}}{\partial x_{\mathrm{i}}}\right)\right]-\frac{2}{3} \mu_{\mathrm{f}} \frac{\partial u_{1}}{\partial x_{1}} \delta_{\mathrm{ij}}
$$

where $\mu$ is the dynamic viscosity and $\delta_{\mathrm{ij}}$ is the kronecker delta.

The energy equation is given as:

$$
\frac{\partial}{\partial x_{\mathrm{i}}}\left(\rho_{\mathrm{f}} c_{p} u_{\mathrm{i}} T\right)=\frac{\partial}{\partial x_{\mathrm{i}}}\left(k_{\mathrm{f}} \frac{\partial T}{\partial x_{\mathrm{i}}}\right)+\frac{\partial}{\partial x_{\mathrm{i}}}\left(u_{\mathrm{j}} \tau_{\mathrm{ij}}\right)
$$

where $k_{\mathrm{f}}$ is the thermal conductivity of fluid and the second term on the right side of the equation is viscous heat dissipation.

The $k$-epsilon turbulent equations are also solved for the turbulent flow and given as:

$$
\begin{gathered}
\rho_{\mathrm{f}} u_{\mathrm{j}} \frac{\partial k}{\partial x_{\mathrm{j}}}=\frac{\partial}{\partial x_{\mathrm{j}}}\left[\left(\mu_{\mathrm{f}}+\frac{\mu_{t}}{\sigma_{k}}\right) \frac{\partial k}{\partial x_{\mathrm{j}}}\right]+\mu_{t} \frac{\partial u_{\mathrm{i}}}{\partial x_{\mathrm{j}}}\left(\frac{\partial u_{\mathrm{i}}}{\partial x_{\mathrm{j}}}+\frac{\partial u_{\mathrm{j}}}{\partial x_{\mathrm{i}}}\right)-\rho_{\mathrm{f}} \varepsilon \\
\rho_{\mathrm{f}} u_{\mathrm{k}} \frac{\partial \varepsilon}{\partial x_{\mathrm{k}}}=\frac{\partial}{\partial x_{\mathrm{k}}}\left[\left(\mu_{\mathrm{f}}+\frac{\mu_{t}}{\sigma_{\varepsilon}}\right) \frac{\partial \varepsilon}{\partial x_{\mathrm{k}}}\right]+\frac{c_{1} \varepsilon}{k} \mu_{t} \frac{\partial u_{\mathrm{i}}}{\partial x_{\mathrm{j}}}\left(\frac{\partial u_{\mathrm{i}}}{\partial x_{\mathrm{j}}}+\frac{\partial u_{\mathrm{j}}}{\partial x_{\mathrm{i}}}\right)-c_{2} \rho_{\mathrm{f}} \frac{\varepsilon^{2}}{k}
\end{gathered}
$$




$$
\mu_{t}=c_{\mu} \rho_{\mathrm{f}} k^{2} / \varepsilon
$$

where $c_{\mu}, c_{1}, c_{2}, \sigma_{k}$ and $\sigma_{\varepsilon}$ are the empirical coefficients.

The flow and heat transfer are ensured to be fully developed by applying the periodic condition to the computation domain in the $z$ direction. The following relationship holds for the velocity at the inlet and outlet of the computation domain:

$$
u_{\mathrm{i}, z=0}=u_{\mathrm{i}, z=L}
$$

The periodic condition for the temperature in the situation of constant heat-flux at the gas-solid interface is given by:

$$
\left(T-T_{\mathrm{b}}\right)_{z=0}=\left(T-T_{\mathrm{b}}\right)_{z=L}
$$

where $T_{\mathrm{b}}$ is the bulk temperature.

The symmetric condition is used for the remaining four boundaries:

$$
\frac{\partial u_{\mathrm{i}}}{\partial x}=0 ; \frac{\partial u_{\mathrm{i}}}{\partial y}=0 ;\left.\frac{\partial T}{\partial x}\right|_{x=0, L}=0 ;\left.\frac{\partial T}{\partial y}\right|_{y=0, L}=0
$$

\subsection{Numerical methodology}

The computation domain for the simulations on the flow and gas-solid interface heat transfer characteristics of coated metal foams is as shown in Fig. 4a) in the situation of no viscous flow presenting in washcoat. Tetrahedral mesh generation is carried out for the bulk zone of the computation domain by the software ANSYS Icem. Additionally, two prism layers are introduced at the gas-solid interface, as shown in Fig. 4b). Standard wall function is adopted for the $k$-epsilon model describing the turbulent phenomenon inside the coated foams. In addition, the dimensionless distance $y^{+}$ is kept to approximately $0.5-2.0$ as recommended by Wehinger et al. (2015). Three-dimensional governing equations (Eqs. (13-19)) are applied to the computation domain. Air is chosen as the working fluid and its physical property parameters are shown in Table 2. The operating environment pressure is assumed to be $101325 \mathrm{~Pa}$. Boundary conditions are set as periodic boundary condition for inlet and outlet, symmetry boundary condition for the remaining four boundaries and no-slip wall and constant heat flux conditions for the gas-solid interface. The convective terms in the momentum and energy equations are discretized using the second-order upwind scheme. The pressure-velocity coupling is approximated by the SIMPLE scheme. The simulations are not terminated until the residuals fall below $1 \times 10^{-5}$ for continuity and momentum equations and $1 \times 10^{-9}$ for energy equation. Moreover, the average temperature at the gas-solid interface is defined to monitor the convergence of the calculations. As an example, the monitor of a case with parameters of $L=0.95 d_{\mathrm{c}}$ and $t_{\mathrm{w}}=100 \mu \mathrm{m}$ in the flow rate $G$ of $4 \times 10^{-7} \mathrm{~kg} / \mathrm{s}$ is shown in Fig. $4 \mathrm{c}$ ). Mesh independence verification for the solution is also carried out using four different grids with element number respectively of $203649,347442,558826$ and 
1530293, as shown in Fig. 4d). The variations of the calculating values are very small for these four meshes with the maximum deviations respectively of $0.04 \%$ and $2.8 \%$ for pressure drop and Nusselt number. The mesh size corresponding to the mesh number of 347442 is here used for mesh generation.

The friction factor is defined for the flow resistance characteristic:

$$
f=\frac{(\Delta p / L) \sqrt{K}}{\rho_{\mathrm{f}} U^{2}}
$$

where $U$ is the superficial velocity and $K$ is the permeability.

The permeability is estimated by Darcy's law for the laminar flow regime:

$$
K=\frac{\mu_{\mathrm{f}} U}{\Delta p / L}
$$

The interface heat transfer Nusselt number is defined for gas-solid interface heat transfer characteristic:

$$
N u_{\mathrm{c}}=\frac{h d_{\mathrm{c}}}{k_{\mathrm{f}}}=\frac{q d_{\mathrm{c}}}{k_{\mathrm{f}}\left(\bar{T}_{\mathrm{s}}-T_{\mathrm{b}}\right)}
$$

where $\bar{T}_{\mathrm{s}}$ is the area-weighted average temperature of the gas-solid interface and $T_{\mathrm{b}}$ is the bulk temperature.

\section{Gas-solid interface heat transfer with viscous flow in washcoat}

\subsection{Governing equations and boundary conditions}

Based on the Knudsen flow theory, the viscous flow occurs in washcoat if the pore size in washcoat is up to the order of micrometers. In this situation, the flow and heat transfer in washcoat should also be considered, in addition to those in fluid zone. The macroscopic mass, momentum and energy conservation equations in dispersed phase (Hsu and Cheng, 1990) are used to describe the physical processes in washcoat.

The macroscopic continuity equation is given as:

$$
\frac{\partial}{\partial x_{\mathrm{i}}}\left(\rho_{\mathrm{f}} \varepsilon_{\mathrm{o}} u_{\mathrm{i}}\right)=0
$$

where $\varepsilon_{\mathrm{o}}$ is the porosity in washcoat.

The macroscopic momentum equation is given as:

$$
\frac{\partial}{\partial x_{\mathrm{j}}}\left(\rho_{\mathrm{f}} \varepsilon_{\mathrm{o}} u_{\mathrm{i}} u_{\mathrm{j}}\right)=-\frac{\partial}{\partial x_{\mathrm{i}}}\left(\varepsilon_{\mathrm{o}} p\right)+\frac{\partial^{2}}{\partial x_{\mathrm{j}}^{2}}\left(\varepsilon_{\mathrm{o}} u_{\mathrm{i}}\right)+\varepsilon_{\mathrm{o}} \rho_{\mathrm{f}} g_{\mathrm{i}}+S
$$

where $S$ is the volume source term caused by macro-porous media.

The rarefaction effect occurs in gas flow through the micro-porous media with a pore size below $90 \mu \mathrm{m}$ (Huang et al., 
2009). They had experimentally proposed a correlation of pressure drop for the flow in micro-porous media with the pore size from $20 \mu \mathrm{m}$ to $150 \mu \mathrm{m}$. The pressure drop of the flow in washcoat is approximated by the correlation of Huang et al. (2009):

$$
S=\frac{163.8}{1+433 \overline{K n}} \cdot u+1.35 \frac{\left(1+3.39 \times 10^{5} \overline{K n} \bar{K}^{1.9}\right)}{(1+433 \overline{K n})^{1 / 2}} \cdot \frac{\left(1-\varepsilon_{\mathrm{o}}\right) \rho_{\mathrm{f}}}{\varepsilon_{\mathrm{o}}^{3} d_{\mathrm{o}}} u^{2}
$$

where $d_{\mathrm{o}}$ is the pore diameter in washcoat.

The macroscopic energy equation is given as:

$$
\frac{\partial}{\partial x_{i}}\left(\varepsilon_{\mathrm{o}} \rho_{\mathrm{f}} c_{p} u_{i} T\right)=\frac{\partial}{\partial x_{i}}\left(k_{e 0} \frac{\partial T}{\partial x_{i}}+k^{\prime}: \frac{\partial T}{\partial x_{i}}\right)
$$

where $k_{e 0}$ is the stagnant thermal conductivity and $k^{\prime}$ is the effective thermal dispersion conductivity.

\subsection{Numerical methodology}

The computation domain is as shown in Fig. 5a) for the simulations on the flow and gas-solid interface heat transfer characteristics of coated metal foams in the situation of viscous flow presenting in washcoat. The computation domain is composed of fluid zone and washcoat zone. Tetrahedral mesh generation is carried out for the bulk zone of fluid flow by the software ANSYS Icem, as shown in Fig. 5b). Additionally, two prism layers are introduced at both sides of the washcoat-fluid interface, as shown in Fig. 5b). The mesh size chosen is the same as that for the case without viscous flow in washcoat. Standard wall function is adopted for the $k$-epsilon model describing the turbulent phenomenon inside fluid zone. In addition, the dimensionless distance $y+$ is kept to approximately $0.5-2.0$ as recommended by Wehinger et al. (2015). The governing equations for continuous phase (Eqs. (13-19)) and the macroscopic equations for dispersed phase (Eqs. (26-29)) are applied to fluid zone and washcoat zone, respectively. Air is chosen as the working fluid and its physical property parameters are shown in Table 2. Based on the Knudsen flow theory, the viscous flow will appear if the Knudsen number is below 0.1 . We assume the pore diameter in washcoat to be $3 \mu \mathrm{m}$ and the porosity to be 0.4 in this work. The operation environment pressure is assumed to be $101325 \mathrm{~Pa}$. Boundary conditions are set as periodic boundary condition for inlet and outlet, symmetry boundary condition for the remaining four boundaries, interior condition for the washcoat-fluid interface and no-slip wall and constant heat flux conditions for the support surface. The convective terms in the momentum and energy equations are discretized using the second-order upwind scheme. The pressure-velocity coupling is approximated by the SIMPLE scheme. The simulations are not terminated until the residuals fall below $1 \times 10^{-5}$ for continuity and momentum equations and $1 \times 10^{-9}$ for energy equation. Moreover, the average temperature at the washcoat-fluid interface and the support surface is defined to monitor the convergence of the calculations. As an example, the monitor of a case with parameters of $L=0.95 d_{\mathrm{c}}$ and $t_{\mathrm{w}}=100 \mu \mathrm{m}$ in the flow rate $G$ of 
$4 \times 10^{-7} \mathrm{~kg} / \mathrm{s}$ is shown in Fig. $5 \mathrm{c}$ ). The total pressure drop in both fluid and washcoat zones is directly exported from the software and the Nusselt number for the gas-solid interface heat transfer is derived using Eq. (25) from calculated temperature field.

\section{Results and discussion}

\subsection{Effective thermal conductivity}

There is at present no experimental data of effective thermal conductivity due to pure conductivity for coated metal foams. To indirectly validate the reliability of the coated metal foam model built in this study, the simulated effective thermal conductivities of coated foams with the conductivity of washcoat equal to that of metal support are compared with the predicted values by some typical correlations for metal foams (Bhattacharya et al., 2002; Ranut, 2015; Singh and Kasana, 2004; Wang et al., 2008; Boomsma and Poulikakos, 2001) summarized in Table 3, as shown in Fig. 6. It can be seen that the simulated values are in agreement with the predicted data by correlations in the changing tendency with the porosity. The deviations are within $30 \%$ for the porosity between 0.83 and 0.98 although the simulated values are higher by a difference than the predicted data during low porosity. To some extent, the geometry model could represent the heat conduction property of coated metal foams with the washcoat thickness below $100 \mu \mathrm{m}$.

Fig. 7 shows the change of effective thermal conductivity with the varying washcoat thickness under the same metal support structure. It can be observed that: (i) For the $\alpha-\mathrm{Al}_{2} \mathrm{O}_{3}$ washcoat, the effective thermal conductivity increases with the increase of the washcoat thickness. This is because the $\alpha-\mathrm{Al}_{2} \mathrm{O}_{3}$ washcoat has a higher conductivity than the working fluid, as shown in Table 2. (ii) For the SBA-15 washcoat, the effective thermal conductivity also increases with the increase of the washcoat thickness for the case with air as working fluid, while it is opposite to the case with water as working fluid. This is due to the fact that the SBA-15 washcoat has a thermal conductivity higher than air but lower than water. This indicates that the washcoat material chosen should have a great thermal conductivity. (iii) Compared to the $\alpha-\mathrm{Al}_{2} \mathrm{O}_{3}$ washcoat, the SBA-15 washcoat has a smaller influence on effective thermal conductivity, below $5 \%$ for the cases studied. This is due to the fact that SBA-15 has a thermal conductivity very close to air and water compared to $\alpha-\mathrm{Al}_{2} \mathrm{O}_{3}$. (iv) The case with water as working fluid shows a higher effective thermal conductivity than that with air as working fluid regardless of the material of metal support for $L=0.95 d_{\mathrm{c}}\left(\varepsilon_{\mathrm{s}}=0.9174 \%\right)$, as shown in Fig. 7a). However, for $L=0.97 d_{\mathrm{c}}$ and $L=0.99 d_{\mathrm{c}}\left(\varepsilon_{\mathrm{s}}>2.46 \%\right)$, the coated copper foams have a higher effective thermal conductivity than the coated aluminum foams regardless of the working fluid, as shown in Figs. $7 \mathrm{~b}$ ) and $7 \mathrm{c}$ ). This is determined by the relative magnitude of volume fraction between metal support zone and fluid zone.

Fig. 8 shows the change of effective thermal conductivity with the varying conductivity of washcoat under the same । coated metal foam structure, where the maximum conductivity of washcoat corresponds to that of metal support. It can 
be seen that: (i) The effective thermal conductivity decreases with the decrease of the conductivity of washcoat. It indicates that the washcoat material chosen should have a great thermal conductivity. (ii) The effective thermal conductivity increases with the increase of $L / d_{\mathrm{c}}$. This is because the volume of metal support increases with the increase of $L / d_{\mathrm{c}}$. Therefore metal foams chosen to be coated are advised to have a low porosity. (iii) The effective thermal conductivity decreases faster with the washcoat conductivity for high $L / d_{\mathrm{c}}$ under the same washcoat thickness. This is due to the fact that the coated volume increases with the increase of $L / d_{\mathrm{c}}$ under the same washcoat thickness because of large surface area for metal foams with high $L / d_{\mathrm{c}}$ or low porosity, as shown in Table 1 and Fig. 10b). Therefore low porosity metal foams are advised to be coated for large loading capacity of catalyst. (iv) The effective thermal conductivity decreases faster with the washcoat conductivity for great washcoat thickness under the same $L / d_{\mathrm{c}}$. This is because the coated volume increases with the washcoat thickness increased. This indicates that the greater the washcoat thickness is, the more remarkable the influence of the washcoat on the effective thermal conductivity. (v) The superiority of copper foams in thermal conductivity to aluminum foams weakens with the decrease of $L / d_{\mathrm{c}}$ or the increase of porosity.

The effective thermal conductivities of coated metal foams are compared with those of packed beds with catalyst pellets, as shown in Fig. 8. We could predict the effective thermal conductivity of packed beds with spherical pellets referring to the work of Wakao (1976), where a chart estimating the effective thermal conductivity is given for a spherical-particles packed bed with large tube-to-particle diameter ratio. It is clearly seen from Fig. 8 that the coated metal foams show a greater effective thermal conductivity than the packed bed with catalyst pellets for all the cases studied. It is essential to point out that the coated FeCrAl foams may be inferior to packed bed with catalyst pellets in effective thermal conductivity considering low conductivity of FeCrAl foams and high volume fraction of solid phase in packed beds.

Comparing the effective thermal conductivity between coated metal foams and metal foams under the same porosity, the washcoat has a significant influence on effective thermal conductivity provided that the washcoat conductivity is different from that of metal support above an order of magnitud. For example, the deviation is up to $80 \%$ in effective thermal conductivity for SBA-15 coated foams with the parameters of $L=0.95 d_{\mathrm{c}}$ and $t_{\mathrm{w}}=20 \mu \mathrm{m}$ although the washcoat just holds $0.9839 \%$ of the unit cell volume, as shown in Fig. 8 . The key reason is that the washcoat has a volume fraction close to the metal support, as shown in Table 1. Undoubtedly, there exists a great deviation using the available empirical correlations for metal foams to predict the effective thermal conductivity of coated metal foams under the same porosity if the washcoat has a very different conductivity from the metal support. It is therefore necessary to propose a correlation of effective thermal conductivity suitable for coated metal foams.

Similar to the situation of metal foams (Bhattacharya et al., 2002; Ranut, 2015; Singh and Kasana, 2004; Wang et al., 
2008; Boomsma and Poulikakos, 2001), we also could propose a correlation of effective thermal conductivity for metal foams with washcoat based on the series-parallel theory. The upper limit of effective thermal conductivity for three phases in parallel to the direction of heat flow path is given as:

$$
k_{\mathrm{II}}=\varepsilon_{\mathrm{f}} k_{\mathrm{f}}+\varepsilon_{\mathrm{w}} k_{\mathrm{w}}+\varepsilon_{\mathrm{s}} k_{\mathrm{s}}
$$

The lower limit of effective thermal conductivity for three phases arranged in series and perpendicular to the direction of heat flow path is given as:

$$
k_{\perp}=\frac{k_{\mathrm{f}} k_{\mathrm{w}} k_{\mathrm{s}}}{\varepsilon_{\mathrm{f}} k_{\mathrm{w}} k_{\mathrm{s}}+\varepsilon_{\mathrm{w}} k_{\mathrm{f}} k_{\mathrm{s}}+\varepsilon_{\mathrm{s}} k_{\mathrm{f}} k_{\mathrm{w}}}
$$

The effective thermal conductivity for three phases arranged in a specific method is comprised of contributions from both these two limiting values. Based on this method, an empirical correlation of effective thermal conductivity for coated metal foams is expressed as:

$$
k_{\mathrm{e}}=F k_{\mathrm{II}}+(1-F) k_{\perp}=F\left(\varepsilon_{\mathrm{f}} k_{\mathrm{f}}+\varepsilon_{\mathrm{w}} k_{\mathrm{w}}+\varepsilon_{\mathrm{s}} k_{\mathrm{s}}\right)+(1-F) \frac{k_{\mathrm{f}} k_{\mathrm{w}} k_{\mathrm{s}}}{\varepsilon_{\mathrm{f}} k_{\mathrm{w}} k_{\mathrm{s}}+\varepsilon_{\mathrm{w}} k_{\mathrm{f}} k_{\mathrm{s}}+\varepsilon_{\mathrm{s}} k_{\mathrm{f}} k_{\mathrm{w}}}
$$

The weighting coefficient $F$ has been fitted to the simulated data of all investigated samples of coated metal foams by minimizing the root mean square deviation. It is observed during the fitting procedure that the weighting coefficient decreases with the increase of $L / d_{\mathrm{c}}$. The parameter $L / d_{\mathrm{c}}$ to some extent represents fraction of solid material in struts and lumps and is related to the volume fraction of metal support $\varepsilon_{\mathrm{s}}$. A fitting function of $F=6.852 \varepsilon_{\mathrm{s}}-0.085$ is obtained for $F$ and $\varepsilon_{\mathrm{s}}$ because the volume fraction of metal support is more in common use than the parameter $L / d_{\mathrm{c}}$. Fig. 9 shows the comparisons of the predicted effective thermal conductivities using Eq. (32) with the simulated data of the unit cell model by CFD. There exists a good agreement between the predicted values and the CFD data with a deviation within $20 \%$. The weighting coefficient $F$ for the coated metal foam model approximately with $\varepsilon_{\mathrm{s}}=2 \%$ is in accordance with those in the Bhattacharya's and Ranut's correlations for metal foams (Bhattacharya et al., 2002; Ranut, 2015). It should be pointed out that the value of weighting coefficient $F$ still needs to be further validated by experimental data.

\subsection{Gas-solid interface heat transfer without viscous flow in washcoat}

The washcoat has a significant influence on the structural characteristic of metal foams. It is easy to understand that the cell diameter decreases with the increase of the washcoat thickness and the strut diameter increases with it. Both porosity and flow area decrease with the washcoat thickness increased, as shown in Figs. 10a) and 10c). The specific surface area increases with the increase of the washcoat thickness, as shown in Fig. 10b). These structural parameters affect the flow and gas-solid interface heat transfer characteristics of metal foams and so does the washcoat.

Fig. 11 shows the change of pressure drop and Nusselt number with the varying washcoat thickness in both laminar 
and turbulent flow regimes. Fig. 11a) is the case of $G=4 \times 10^{-7} \mathrm{~kg} / \mathrm{s}$ corresponding to the Reynolds number $1.72<\operatorname{Re}_{\mathrm{K}}<2.03$ (in laminar flow) for various structural parameter $L / d_{\mathrm{c}}$. Fig. $11 \mathrm{~b}$ ) is the case of $G=1.6 \times 10^{-5} \mathrm{~kg} / \mathrm{s}$ corresponding to the Reynolds number $69.72<R e_{\mathrm{K}}<78.14$ (in turbulent flow) for various structural parameter $L / d_{\mathrm{c}}$. It can be observed that the pressure drop increases with the increase of the washcoat thickness and the Nusselt number decreases with it. Fig. 12 shows the nephograms of the mainstream velocity in the planes of $y=0$ and $y=L / 4$ for different washcoat thickness. The positions of the planes of $y=0$ and $y=L / 4$ in unit cell are also shown in Fig. 12e). It can be indicated from Figs. 12a) and 12b) that the thickness of the flow boundary layer increases with the increase of surface area, resulting in large friction effect and thermal boundary layer near the gas-solid interface. In addition, the flow disturbance is strengthened in bulk zone because of the decrease of porosity and flow area, leading to large inertia effect. It can be seen from Figs. 12c) and 12d) that the flow stagnation zones near both windward and leeward sides of the struts enlarge with the strut diameter increased. All of these factors are the explanation of the deterioration of flow and interface heat transfer characteristics with the washcoat thickness increased.

The simulated friction factor $f$ for metal foams with and without washcoat in both laminar and turbulent flow regimes is drawn as a function of Reynolds number $R e_{\mathrm{K}}$, as shown in Fig. 13. It can be seen that the hydrodynamic characteristic curve climbs with the increase of the washcoat thickness for both laminar and turbulent flow regimes. This is because the Ergun's coefficient $C_{E}$ representing inertial effect strongly depends on the shape of the strut and geometric structure (Paek et al., 2000). In addition, we compare the simulated friction factors of coated metal foams with the predicted ones by the experimental correlations of metal foams (Vafai and Tien, 1982; Paek et al., 2000; Inayat et al., 2016). The Ergun equation relating pressure gradient to flow velocity and geometric parameters is given as:

$$
-\frac{\Delta p}{L}=\frac{\mu_{\mathrm{f}}}{K} U+\frac{\rho_{\mathrm{f}} C_{E}}{\sqrt{K}} U^{2}
$$

where $C_{E}$ is a coefficient representing inertial effect.

A general dimensionless equation is derived by introducing the Reynolds number $R e_{\mathrm{K}}$ and the friction factor $f$ as:

$$
f=\frac{1}{\operatorname{Re}_{\mathrm{K}}}+C_{E}
$$

The value of $C_{E}$ is 0.105 and 0.057 respectively in the correlations of Paek et al. (2000) and Vafai and Tien (1982) for metal foams.

More importantly, a new pressure drop correlation for open-cell foams (Inayat et al., 2016) takes into account the influence of strut shape and geometric tortuosity on the inertial coefficient $C_{E}$. Its expression is as follows:

$$
-\frac{\Delta p}{L}=32 \tau^{2} \frac{\mu_{\mathrm{f}}}{\varepsilon_{\mathrm{f}} d_{\mathrm{h}}^{2}} U+\frac{\tau^{3}}{2} \frac{\rho_{\mathrm{f}}}{\varepsilon_{\mathrm{f}}^{2} d_{\mathrm{h}}} U^{2}
$$


where $\tau$ is the tortuosity and its expression is $\tau=1+0.25 d_{\mathrm{p}} S_{\mathrm{v}} / \varepsilon_{\mathrm{f}}$.

This pressure drop correlation is transformed by introducing the Reynolds number $R e_{\mathrm{K}}$ and the friction factor $f$ as:

$$
f=\frac{1}{\operatorname{Re}_{\mathrm{K}}}+\frac{\tau^{2} \sqrt{\varepsilon_{\mathrm{f}}}}{8 \sqrt{2} \varepsilon_{\mathrm{f}}^{2}}
$$

It is indicated from Eq. (36) that the parameter $C_{E}$ depends on the structural parameter of foams, namely the porosity. The parameter $C_{E}$ increases with the decrease of the porosity, which may explain why the hydrodynamic characteristic curve climbs with the increase of the washcoat thickness. The pressure drop of coated metal foams can be therefore predicted using the experimental correlation of metal foams (Inayat et al., 2016). Compared to the predicted values by the correlation of Inayat et al. (2016), the underestimation of the coated metal foam model with $L / d_{\mathrm{c}}=0.95$ on pressure drop is because the metal foam model with $L / d_{\mathrm{c}}=0.95$ has an anomaly small strut diameter, just $39.6913 \mu \mathrm{m}$.

The simulated Nusselt number based on the strut diameter $N u_{s}$ describing the interface heat transfer characteristic of coated metal foams in turbulent flow is also drawn as a function of Reynolds number based on the strut diameter $R e_{\max }$, as shown in Fig. 14. It can be seen that the interface heat transfer characteristic curve for coated metal foams climbs with the increase of the washcoat thickness. Moreover, the simulated values are compared with the predicted ones by the experimental correlation of the gas-solid heat transfer coefficient for coated metal foams (Groppi et al., 2007), as shown in Fig. 14. The correlation has a fitted range of $30<R e_{\max }<320$ for the Reynolds number and $280 \mu \mathrm{m}<d_{\mathrm{s}}<820 \mu \mathrm{m}$ for the strut diameter. It is observed that the simulated values for $L / d_{\mathrm{c}}=0.99$ are in good agreement with the predicted data by the correlation. However, the simulated values for $L / d_{\mathrm{c}}=0.97$ and $L / d_{\mathrm{c}}=0.95$ are less than the predicted ones, especially for $L / d_{\mathrm{c}}=0.95$. This may be due to the fact that the coated metal foam model with $L / d_{\mathrm{c}}=0.97$ and $L / d_{\mathrm{c}}=0.95$ have a small strut diameter far beyond the range of the correlation, especially for $L / d_{\mathrm{c}}=0.95$.

\subsection{Gas-solid interface heat transfer with viscous flow in washcoat}

Fig. 15 shows the comparisons of pressure drop for the cases with and without viscous flow within washcoat in both laminar and turbulent flow regimes. Fig. 15a) is the case of $G=4 \times 10^{-7} \mathrm{~kg} / \mathrm{s}$ (in laminar flow) for various structural parameter $L / d_{\mathrm{c}}$. It can be seen that compared to the situation without viscous flow in washcoat, there is a smaller pressure drop for that with viscous flow in washcoat. This is due to the fact that the friction resistance decreases due to the appearing of velocity at the washcoat-fluid interface. Moreover, the decreasing magnitude of pressure drop increases with the washcoat thickness increased because of the enhancement of viscous flow at the washcoat-fluid interface. Fig. $15 \mathrm{~b}$ ) is the case of $G=1.6 \times 10^{-5} \mathrm{~kg} / \mathrm{s}$ (in turbulent flow) for various structural parameter $L / d_{\mathrm{c}}$. It can be seen that the case with viscous flow in washcoat shows a greater pressure drop than that without. This is because the turbulent intensity is remarkedly enhanced due to the appearing of viscous velocity at the washcoat-fluid interface and the great flow 
resistance in washcoat also makes a contribution to the deterioration of flow characteristic. In addition, the increasing magnitude of pressure drop increases with the washcoat thickness increased due to the enhancement of the turbulent intensity. The pressure drop in the case with viscous flow in washcoat increases by approximately 2.5 times compared to that without for $t_{\mathrm{w}}=100 \mu \mathrm{m}$. It should be noted that there exists a far greater viscous flow resistance in washcoat with the pore diameter of $3 \mu \mathrm{m}$ than in macro-scale porous media, so the hydrodynamic characteristic may be improved with the pore diameter increased.

Fig. 16 shows the comparisons of gas-solid interface heat transfer for the cases with and without viscous flow within washcoat in both laminar and turbulent flow regimes for various structural parameter $L / d_{\mathrm{c}}$. It can be seen that the case with viscous flow in washcoat shows a greater interface heat transfer than that without for both laminar and turbulent flows. Moreover, the enhanced magnitude of interface heat transfer increases with the washcoat thickness increased. There is a maximum enhancement of gas-solid interface heat transfer close to 3 times in the case of $L / d_{\mathrm{c}}=0.95$ and $t_{\mathrm{w}}=100 \mu \mathrm{m}$ in laminar flow. More excitingly, the enhancement in turbulent flow goes so far as to 13 times for the same case, far greater than in laminar flow. However, its pressure drop is just increased by 2.5 times.

In addition, it is noted that the gas-solid interface heat transfer of coated metal foams has something to do with the structural characteristic of metal foams, as shown in Figs. 11 and 16. The gas-solid interface heat transfer increases with the decrease of $L / d_{\mathrm{c}}$ for the cases both with and without viscous flow in washcoat. The coated metal foams with low $L / d_{\mathrm{c}}$ have a smaller pressure drop for the cases both with and without viscous flow in washcoat. Therefore, metal foams with excellent flow and heat transfer characteristics are advised to be chosen for strongly exo-/endo-thermic catalytic reactors.

In industrial preparation process, the washcoat with micro pores is advised to be prepared to make the viscous flow occur in washcoat. This will make the performance of metal foam reactors further improved on the existing basis. This idea also can provide a guideline to the washcoat preparation of other structured catalysts.

\section{Conclusions}

In this study, 3D CFD simulations on effective thermal conductivity and gas-solid interface heat transfer of metal foams with and without washcoat were carried out using a microscopic approach. At first, a periodic unit cell model for coated metal foams was built for various structural parameters. Then, we made a detailed study on the influence of the washcoat on thermal transport properties of metal foams. The major conclusions can be drawn as follows:

(1) The washcoat has a significant influence on effective thermal conductivity of metal foams because it has a volume fraction close to the metal support. On condition that the conductivity of washcoat largely differs from that of metal support, there is a great deviation if we predict the effective thermal conductivity of coated metal foams using the available empirical correlations for metal foams under the same porosity. Therefore, a new correlation of effective 
thermal conductivity suitable for coated metal foams is proposed by considering the washcoat as a separate phase.

(2) The washcoat has a significant influence on the flow and gas-solid interface heat transfer of metal foams. Pressure drop increases with the increase of the washcoat thickness and gas-solid interface heat transfer decreases with it. The thickening of flow boundary layer near the interface and the enlarging of the flow stagnation zone in both windward and leeward sides of the struts are the main reasons resulting in the deterioration of flow and interface heat transfer. Both the hydrodynamic and interface heat transfer characteristic curves of coated metal foams climb with the increase of the washcoat thickness for both laminar and turbulent flows. The correlation of pressure drop proposed by Inayat et al. (2016) for metal foams is suitable for coated metal foams.

(3) The viscous flow within the washcoat significantly enhances the gas-solid interface heat transfer of coated metal foams. For the cases studied, the maximum enhancement of gas-solid interface heat transfer reaches 3 times for laminar flow and goes so far as to 13 times for turbulent flow. The enhancement of gas-solid interface heat transfer increases with the washcoat thickness increased. The metal foams with excellent flow and interface heat transfer characteristics are advised to be coated for strongly exo-/endo-thermic catalytic reactors.

In the near future, we will study the influence of washcoat on the radiation heat transfer characterstic of metal foams and carry out an experimental study on thermal transport properties of coated metal foams to support the obtained theoretical results.

\section{Nomenclature}

$a$

A

$c_{p}$

$d_{\mathrm{c}}$

$d_{\mathrm{o}}$

$d_{\mathrm{p}}$

$d_{\mathrm{s}}$

half of the length of the unit cell (m)

the flow area in inlet $(\mathrm{J} / \mathrm{kg} / \mathrm{K})$

heat capacity $(\mathrm{J} / \mathrm{kg} / \mathrm{K})$

cell diameter (m)

the diameter of micro-pores in washcoat (m)

pore diameter (m)

the mean strut diameter $(\mathrm{m})$

the friction factor

acceleration of gravity $\left(\mathrm{m} / \mathrm{s}^{2}\right)$

interface heat transfer coefficient $\left(\mathrm{W} / \mathrm{m}^{2} / \mathrm{K}\right)$

thermal conductivity $(\mathrm{W} / \mathrm{m} / \mathrm{K})$

thermal conductivity of gas mixture $(\mathrm{W} / \mathrm{m} / \mathrm{K})$

effective thermal conductivity $(\mathrm{W} / \mathrm{m} / \mathrm{K})$ 


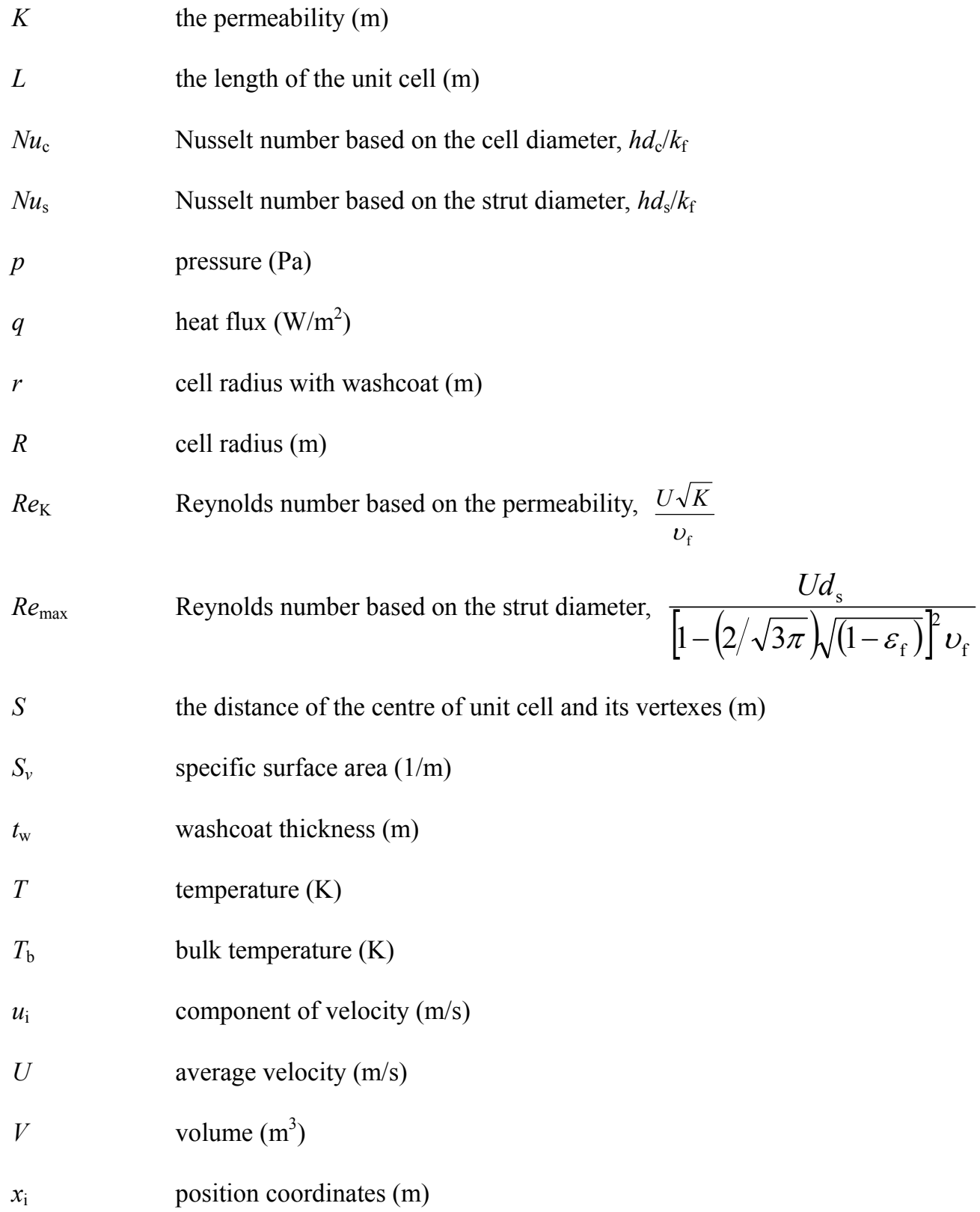

Greek Symbols

$\varepsilon$

$\varepsilon_{\mathrm{o}} \quad$ the porosity in washcoat

$\rho \quad$ density $\left(\mathrm{kg} / \mathrm{m}^{3}\right)$

$\mu$

Subscripts

$\begin{array}{ll}f & \text { fluid } \\ s & \text { support } \\ w & \text { washcoat }\end{array}$




\section{Acknowledgements}

This research is supported by the National Natural Science Foundation of China (51276181).

\section{References}

Bhattacharya, A., Calmidi, V., Mahajan, R., 2002. Thermophysical properties of high porosity metal foams. Int. J. Heat Mass Transf. 45, 1017-1031.

Bianchi, E., Heidig, T., Visconti, C.G., Groppi, G., Freund, H., Tronconi, E., 2012. An appraisal of the heat transfer properties of metallic open-cell foams for strongly exo-/endo-thermic catalytic processes in tubular reactors. Chem. Eng. J. 198-199, 512-528.

Bianchi, E., Heidig, T., Visconti, C.G., Groppi, G., Freund, H., Tronconi, E., 2013. Heat transfer properties of metal foam supports for structured catalysts: Wall heat transfer coefficient. Catal. Today 216, 121-134.

Bianchi, E., Heidig, T., Visconti, C.G., Groppi, G., Freund, H., Tronconi, E., 2015. Numerical simulation of heat transfer in the near-wall region of tubular reactors packed with metal open-cell foams. Chem. Eng. J. 264, 268-279.

Boomsma, K., Poulikakos, D., 2001. On the effective thermal conductivity of a three-dimensionally structured fluid-saturated metal foams. Int. J. Heat Mass Transf. 44 (4), 1827-1836.

Calmidi, V.V., Mahajan, R.L., 2000. Forced convection in high porosity metal foams. J. Heat Transf. 122, 557-565.

Chin, P., Sun, X., Roberts, G.W., Spivey, J.J., 2006. Preferential oxidation of carbon monoxide with iron-promoted platinum catalysts supported on metal foams. Appl. Catal. A Gen. 302, 22-31.

Coquard, R., Rochais, D., Baillis, D., 2012. Conductive and radiative heat transfer in ceramic and metal foams at fire temperatures. Fire Technol. 48, 699-732.

De Wild, P.J., Verhaak, M.J.F.M., 2000. Catalytic production of hydrogen from methanol. Catal. Today 60, 3-10.

Dietrich, B., Fischedick, T., Heissler, S., Weidler, P.G., Woll, C., Kind, M., 2014. Optical parameters for characterization of thermal radiation in ceramic sponges-Experimental results and correlation. Int. J. Heat Mass Transf. 79, $655-665$.

Dietrich, B., Kind, M., Martin, H., 2011. Axial two-phase thermal conductivity of ceramic sponges-Experimental results and correlation. Int. J. Heat Mass Transf. 54, 2276-2282.

Fino, D., Russo, N., Saracco, G., Specchia, V., 2005. Multifunctional filter for treatment of the flue gases from municipal waste incinerators. Ind. Eng. Chem. Res. 44, 9542-9548.

Fourie, J.G., Du Plessis, J.P., 2002. Pressure drop modeling in cellular metallic foams. Chem. Eng. Sci. 57. 2781-2789.

Garrido, G.I., Patcas, F.C., Lang, S., Kraushaar-Czarnetzki, B., 2008. Mass transfer and pressure drop in ceramic foams: A description for different pore sizes and porosities. Chem. Eng. Sci. 63, 5202-5217. 
Giani, L., Groppi, G., Tronconi, E., 2005. Heat transfer characterization of metallic foams. Ind. Eng. Chem. Res. 44, 9078-9085.

Giani, L., Groppi, G., Tronconi, E., 2005. Mass-transfer characterization of metallic foams as supports for structured catalysts. Ind. Eng. Chem. Res. 44, 4993-5002.

Groppi, G., Giani, L., Tronconi, E., 2007. Generalized correlation for gas/solid mass-transfer coefficients in metallic and ceramic foams. Ind. Eng. Chem. Res. 46, 3955-3958.

Hetsroni, G., Gurevich, M., Rozenblit, R., 2008. Natural convection in metal foams strips with internal heat generation. Exp. Therm. Fluid Sci. 32, 1740-1747.

Hsu, C.T., Cheng, P., 1990, Thermal dispersion in a porous medium. Int. J. Heat Mass Transf. 45 (8), 1587-1597.

Huang, C.L., Feng, Y.H., Zhang, X.X., Li, J., Wang, G., 2013. Thermal conductivity of a kind of mesoporous silica SBA-15. Chinese Phys. B 22 (6), 064401-1-5.

Huang, Y.L., Jiang, P.X., Xu, R.N., 2009. Experimental investigations of gas flow characteristics through microporous media. Chinese J. Eng. Thermophys. 30 (8), 1360-1362.

Inayat, A., Freund, H., Zeiser, T., Schwieger, W., 2011. Determining the specific surface area of ceramic foams: Thetetrakaidecahedra model revisited. Chem. Eng. Sci. 66, 1179-1188.

Inayat, A., Klumpp, M., Lammermann, M., Freund, H., Schwieger, W., 2016. Development of a new pressure drop correlation for open-cell foam based completely on theoretical grounds: Taking into account strut shape and geometric tortuosity. Chem. Eng. J. 287, 704-719.

Krishnan, S., Murthy, J.Y., Garimella, S.V., 2006. Direct simulation of transport in open-cell metal foams. J. Heat Transf. 128 (2006) 793-799.

Liu, H., Zhao, J.D., Li, C.Y., Ji, S.F., 2005. Conceptual design and CFD simulation of a novel metal-based monolith reactor with enhanced mass transfer. Catal. Today 105, 401-406.

Mendes, M.A.A., Ray, S., Trimis, D., 2013. A simple and efficient method for the evaluation of effective thermal conductivity of open-cell foams-like structures. Int. J. Heat Mass Transf. 66, 412-422.

Mendes, M.A.A., Skibina, V., Talukdar, P., Wulf, R., Gross, U., Trimis, D., Ray, S., 2014. Experimental validation of simplified conduction-radiation models for evaluation of effective thermal conductivity of open-cell metal foams at high temperatures. Int. J. Heat Mass Transf. 78, 112-120.

Mendes, M.A.A., Talukdar, P., Ray, S., Trimis, D., 2014. Detailed and simplified models for evaluation of effective thermal conductivity of open-cell porous foams at high temperatures in presence of thermal radiation, Int. J. Heat Mass Transf. 68, 612-624.

Novak, V., Koci, P., Gregor, T., Choi, J.S., Stepanek, F., Marek, M., 2013. Effect of cavities and cracks on diffusivity in । 
coated catalyst layer. Catal. Today 216,142-149.

Paek, J.W., Kang, B.H., Kim, S.Y., Hyun, J.M., 2000. Effective thermal conductivity and permeability of aluminum foams materials. Int. J. Thermophys. 21 (2), 453-464.

Peng, Y., Richardson, J.T., 2004. Properties of ceramic foams catalyst supports: one-dimensional and two-dimensional heat transfer correlations. Appl. Catal. A Gen. 266, 235-244.

Ranut, P., 2015. On the effective thermal conductivity of aluminum metal foams: Review and improvement of the available empirical and analytical models. Appl. Therm. Eng. available online.

Richardson, J.T., Hung, J.K., 2003a. Carbon dioxide reforming with Rh and Pt-Re catalysts dispersed on ceramic foam supports, Appl. Catal. A Gen. 255, 69-82.

Singh, R., Kasana, H., 2004. Computational aspects of effective thermal conductivity of highly porous metal foams. Appl. Therm. Eng. 24, 1841-1849.

Vafai, K., Tien, C.L., 1982. Boundary and inertia effects on convective mass transfer in porous media. Int. J. Heat Mass Transf. 25, 1183-1190.

Wakao, N., 1976. Particle-to-fluid transfer coefficients and fluid diffusivities at low flow rate in packed beds. Chem. Eng. Sci. 31, 1115-1122.

Wang, J., Carson, J., Willix, J., North, M., Cleland, D., 2008. A symmetric and interconnected skeleton structural (SISS) model for predicting thermal and electrical conductivity and Young's modulus of porous foams. Acta. Mater. 56, $5138-5146$.

Wehinger, G.D., Eppinger, T., Kraume, M., 2015. Detailed numerical simulations of catalytic fixed-bed reactors: Heterogeneous dry reforming of methane. Chem. Eng. Sci. 122, 197-209.

Williams, K.A., Schmidt, L.D., 2006. Catalytic autoignition of higher alkane partial oxidation on Rh-coated foams. Appl. Catal. A Gen. 299, 30-45.

Younis, L.B., Viskanta, R., 1993. Experimental determination of the volumetric heat transfer coefficient between stream of air and ceramic foams. Int. J. Heat Mass Transf. 36 (6), 1425-1434.

Yu, X.H., Wen, Z.Z., Lin, Y., Tu, S.T., Wang, Z.D., Yan, J.Y., 2010. Intensification of biodiesel synthesis using metal foams reactors. Fuel 89, 3450-3456.

Zhang, B.J., Davis, S.A., Mann, S., 2002. Starch gel templating of spongelike macroporous silicalite monoliths and mesoporous films, Chem. Mater. 14, 1369-1375.

Zhao, C.Y., 2012. Review on thermal transport in high porosity cellular metal foams with open cells. Int. J. Heat Mass Transf. 55, 3618-3632.

Zhao, C.Y., Dai, L.N., Tang, G.H., Qu, Z.G., Li, Z.Y., 2010. Numerical study of natural convection in porous media 
(metals) using Lattice Boltzmann Method (LBM). Int. J. Heat Fluid Flow 31, 925-934.

Zhao, C.Y., Lu, T.J., Hodson, H.P., 2005. Natural convection in metal foams with open cells. Int. J. Heat Mass Transf. 48, $2452-2463$.

Zhao, C.Y., Lu, T.J., Hodson, H.P., 2004. Thermal radiation in ultralight metal foams with open cells. Int. J. Heat Mass Transf. 47, 2927-2939.

Zhao, C.Y., Lu, T.J., Hodson, H.P., Jackson, J.D., 2004. The temperature dependence of effective thermal conductivity of open-celled steel alloy foams. Mater. Sci. Eng. A 367, 123-131.

\section{Figure Captions}

Fig. 1. Scheme of coated metal foams. a) Metal foam support; b) Coated metal foams; c) Unit cell.

Fig. 2. Comparisons of specific surface areas of the coated metal foam model with the predicted ones by the correlations.

Fig. 3. Simulations on effective thermal conductivity. a) Geometry model; b) Mesh generation; c) Monitors of temperature; d) Mesh independence verification.

Fig. 4. Simulations on gas-solid interface heat transfer without viscous flow in washcoat. a) Geometry model; b) Mesh generation; c) Monitor of temperature; d) Mesh independence verification.

Fig. 5. Simulations on gas-solid interface heat transfer with viscous flow in washcoat. a) Geometry model; b) Mesh generation; c) Monitors of temperature.

Fig. 6. Comparisons of the simulated effective thermal conductivity of coated foams with the conductivity of washcoat equal to that of metal support with the predicted values by some typical correlations for metal foams. a) Aluminia-air; $b$ ) Copper-air.

Fig. 7. The effective thermal conductivity of coated metal foams with the varying thickness of washcoat. a) $L=0.95 d_{\mathrm{c}}$; b) $\left.L=0.97 d_{\mathrm{c}} ; \mathrm{c}\right) L=0.99 d_{\mathrm{c}}$.

Fig. 8. The effective thermal conductivity of coated metal foams with the varying conductivity of washcoat. a) $t_{\mathrm{w}}=20 \mu \mathrm{m}$; b) $t_{\mathrm{w}}=50 \mu \mathrm{m}$; c) $t_{\mathrm{w}}=100 \mu \mathrm{m}$.

Fig. 9. Comparisons of the predicted effective thermal conductivity by the present correlation and the simulated ones.

Fig. 10. Structural parameters of coated metal foams as a function of the washcoat thickness. a) Porosity; b) Specific surface area; c) Flow area of inlet.

Fig. 11. Pressure drop and Nusselt number as a function of the washcoat thickness. a) Laminar flow; b) Turbulent flow.

Fig. 12. Nephograms of velocity in the planes of $y=0$ and $y=L / 4$ for metal foams with the washcoat thickness of $20 \mu \mathrm{m}$ and $100 \mu \mathrm{m}$. a) $t_{\mathrm{w}}=20 \mu \mathrm{m}, y=0$; b) $t_{\mathrm{w}}=100 \mu \mathrm{m}, y=0$; c) $t_{\mathrm{w}}=20 \mu \mathrm{m}, y=L / 4$; d) $t_{\mathrm{w}}=100 \mu \mathrm{m}, y=L / 4$; e) The positions of planes of $y=0$ and $y=L / 4$ in unit cell.

Fig. 13. The hydrodynamic characteristic of coated metal foams. a) $L / d_{\mathrm{c}}=0.99$; b) $L / d_{\mathrm{c}}=0.97$; c) $L / d_{\mathrm{c}}=0.95$. 
Fig. 14. The interface heat transfer characterstic of coated metal foams in turbulent flow (The two dash lines respectively represent the low and up limits of $R e_{\max }$ for Groppi et al.'s correlation).

Fig. 15. Comparisons of the pressure drop for coated metal foams with and without viscous flow in washcoat. a) $G=4 \times$ $10^{-7} \mathrm{~kg} / \mathrm{s}$, laminar flow; b) $G=1.6 \times 10^{-5} \mathrm{~kg} / \mathrm{s}$, turbulent flow.

Fig. 16. Comparisons of the Nusselt number for coated metal foams with and without viscous flow in washcoat. a) $G=4$ $\times 10^{-7} \mathrm{~kg} / \mathrm{s}$, laminar flow; b) $G=1.6 \times 10^{-5} \mathrm{~kg} / \mathrm{s}$, turbulent flow. 

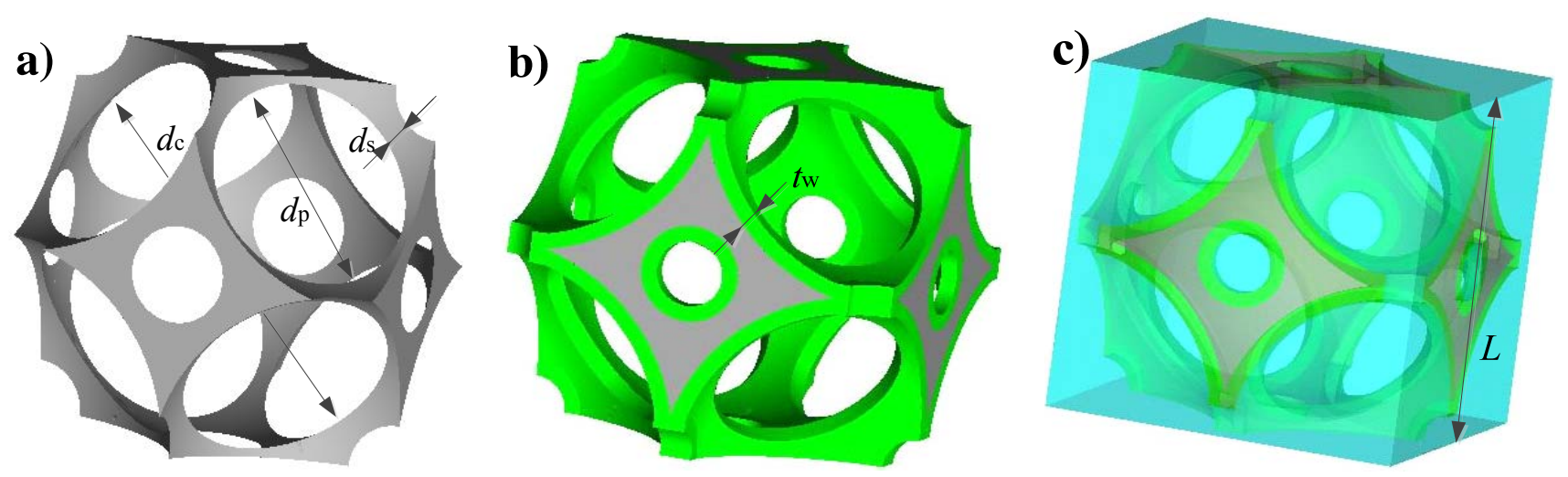

Fig. 1. Scheme of coated metal foams. a) Metal foam support; b) Coated metal foams; c) Unit cell.

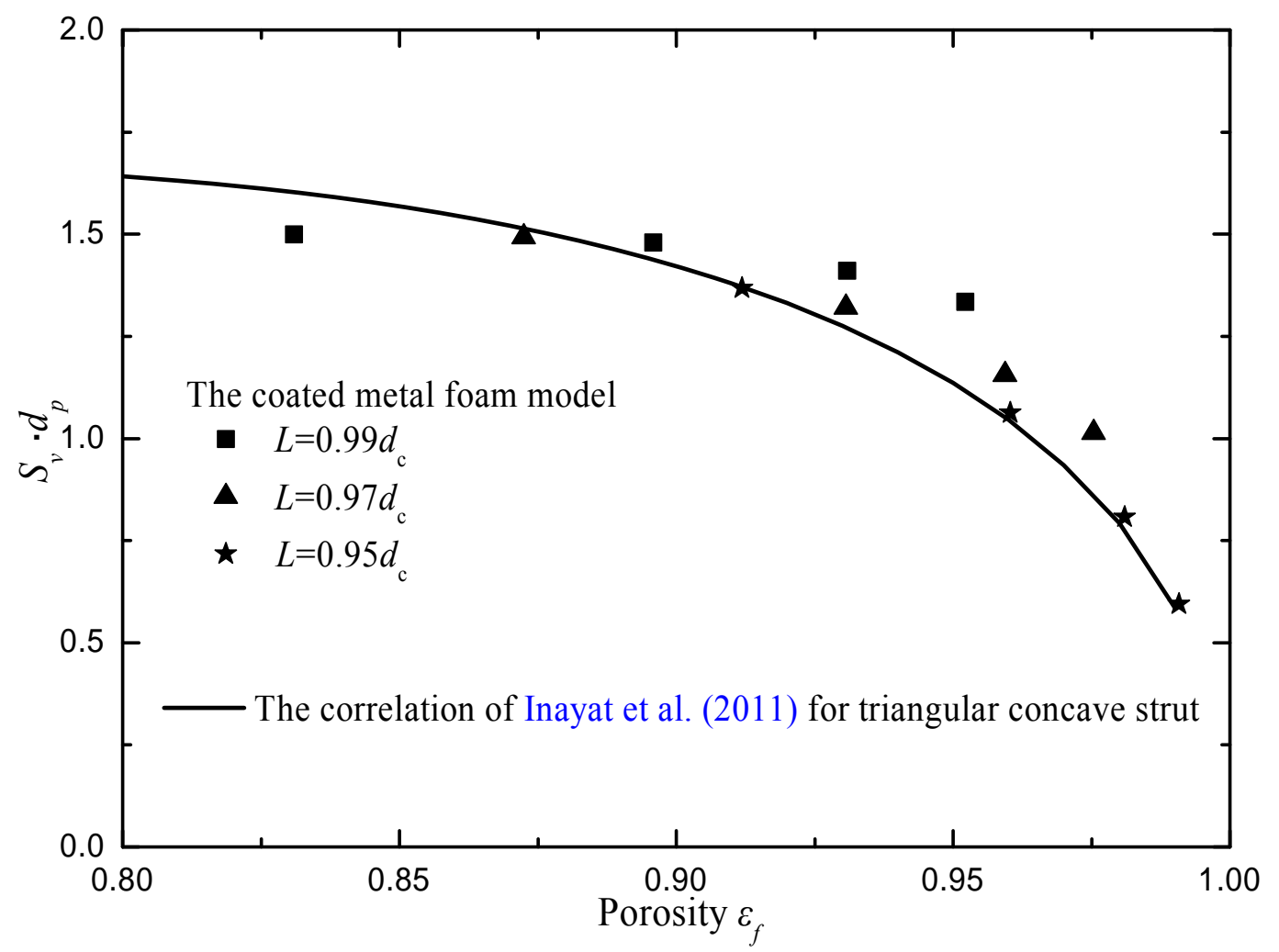

Fig. 2. Comparisons of specific surface areas of the coated metal foam model with the predicted ones by the correlations. 

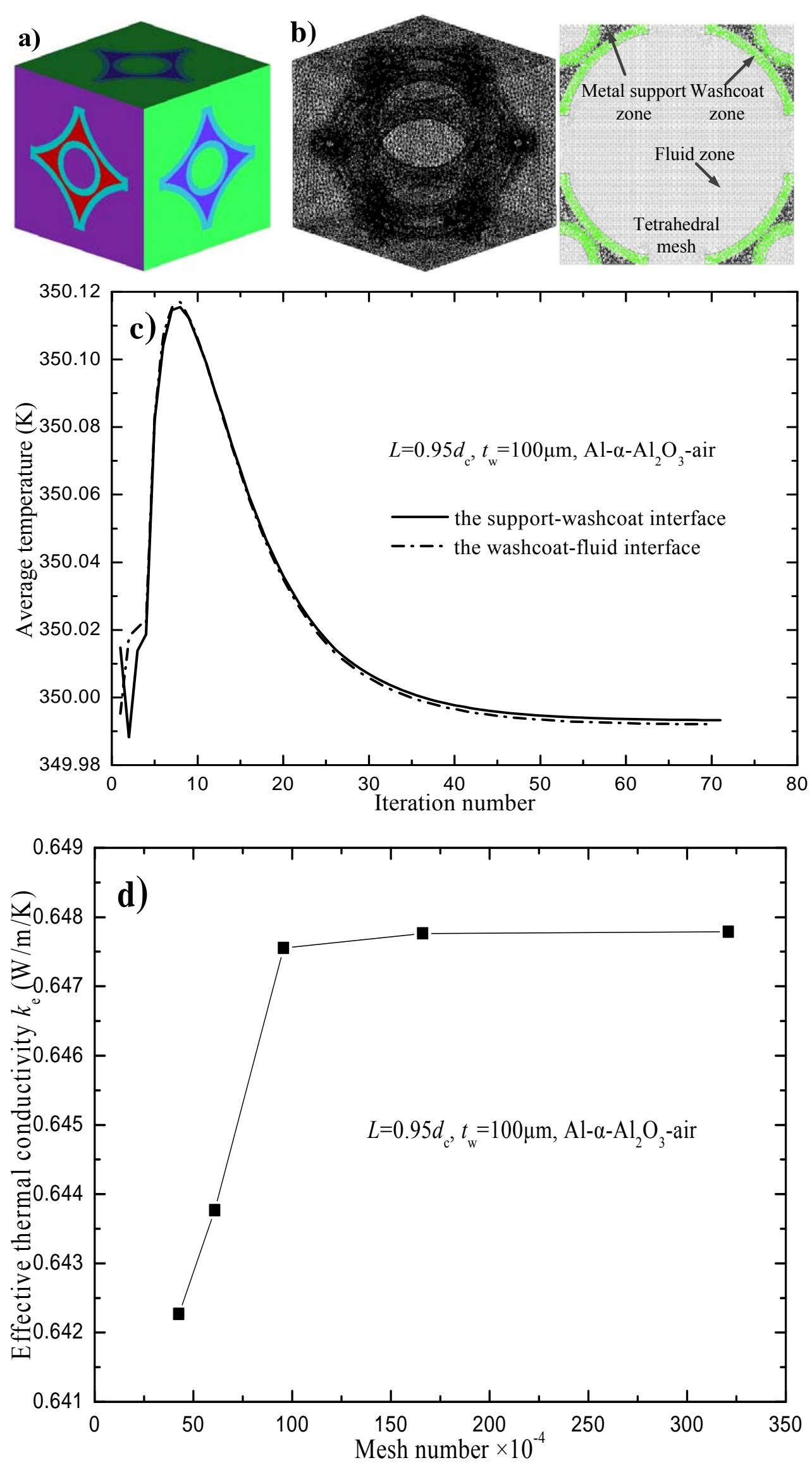

Fig. 3. Simulations on effective thermal conductivity. a) Geometry model; b) Mesh generation; c) Monitors of temperature; d) Mesh independence verification. 

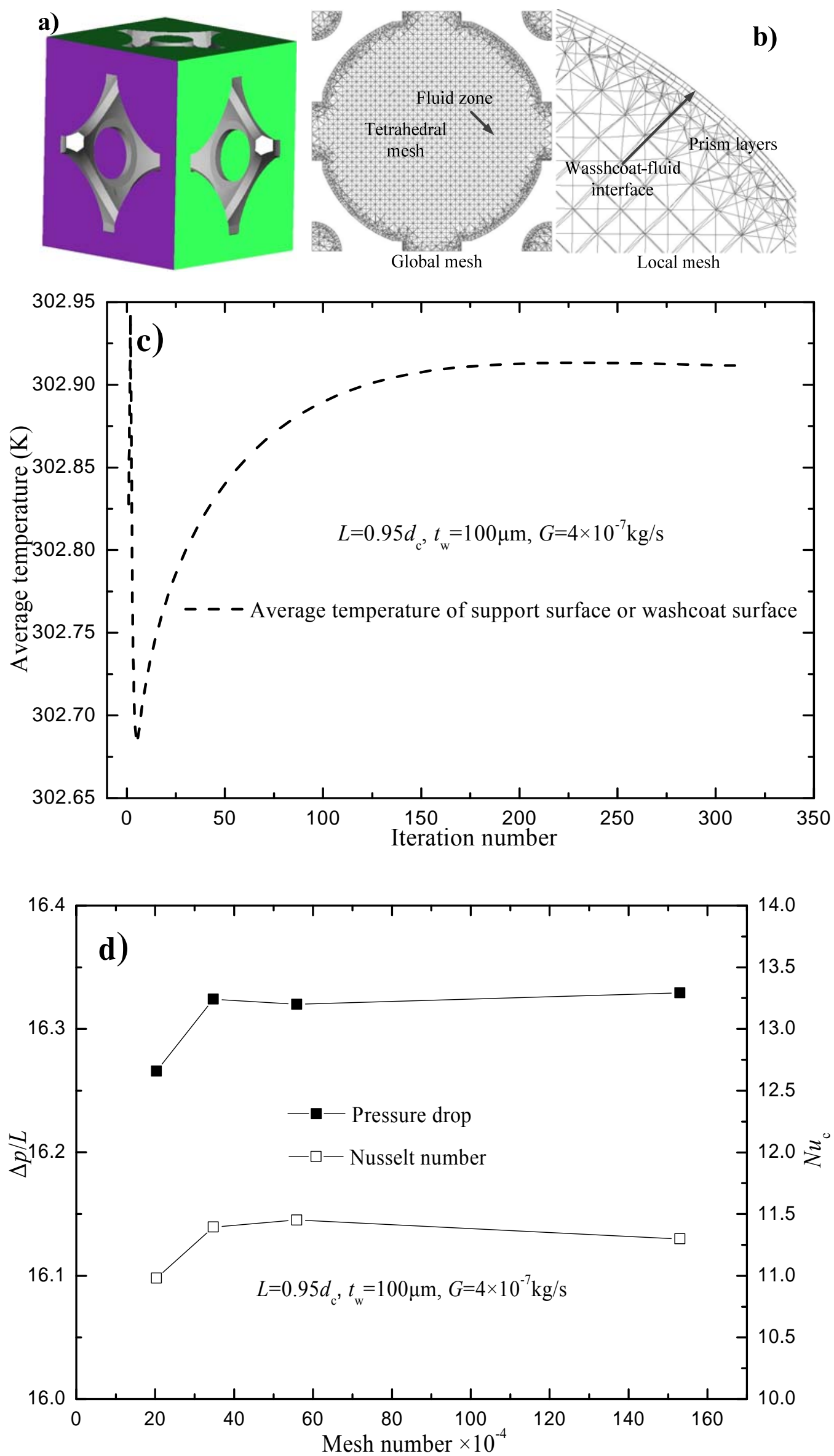

Fig. 4. Simulations on gas-solid interface heat transfer without viscous flow in washcoat. a) Geometry model; b) Mesh generation; c) Monitor of temperature; d) Mesh independence verification. 

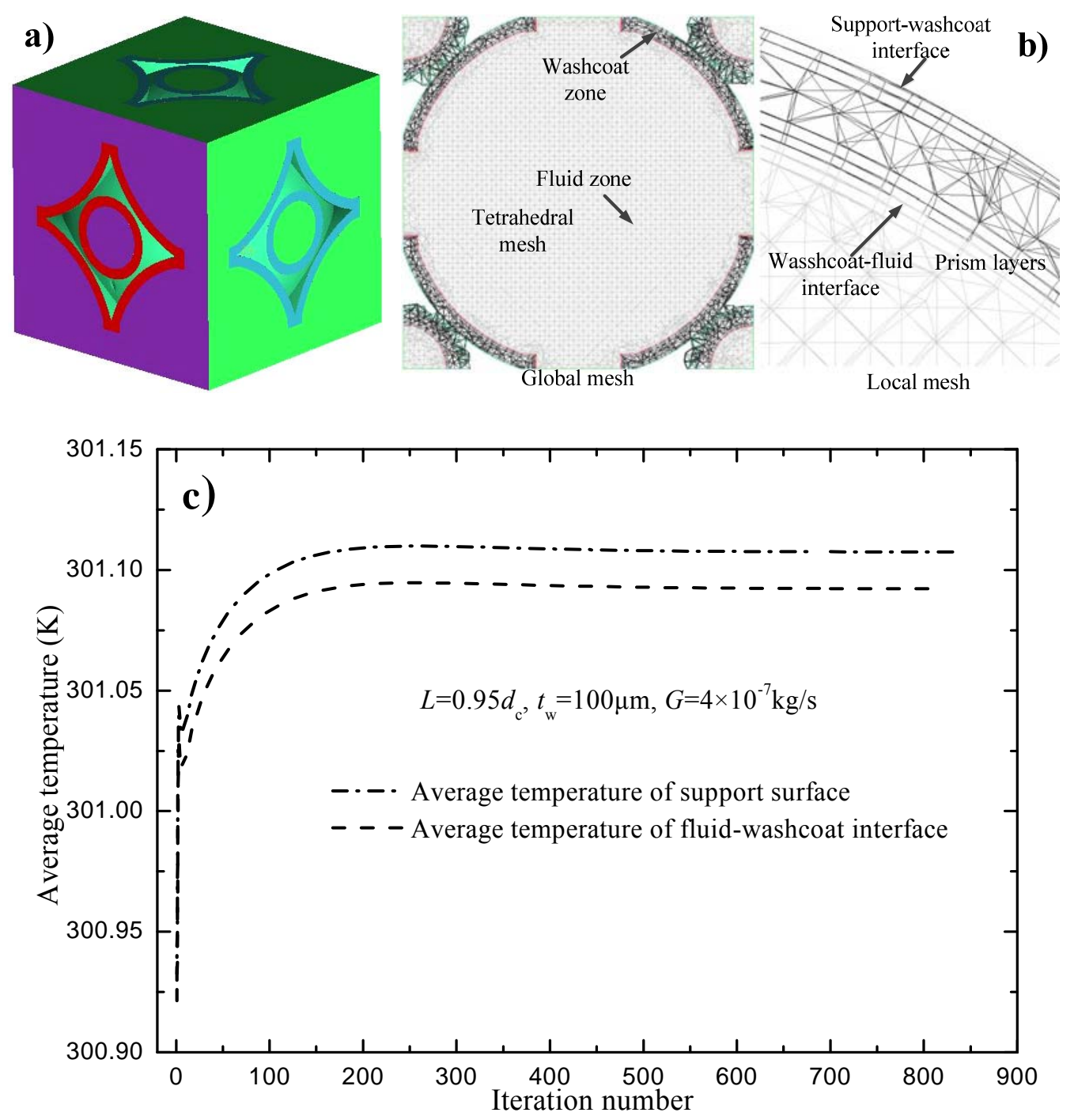

Fig. 5. Simulations on gas-solid interface heat transfer with viscous flow in washcoat. a) Geometry model; b) Mesh generation; c) Monitors of temperature. 

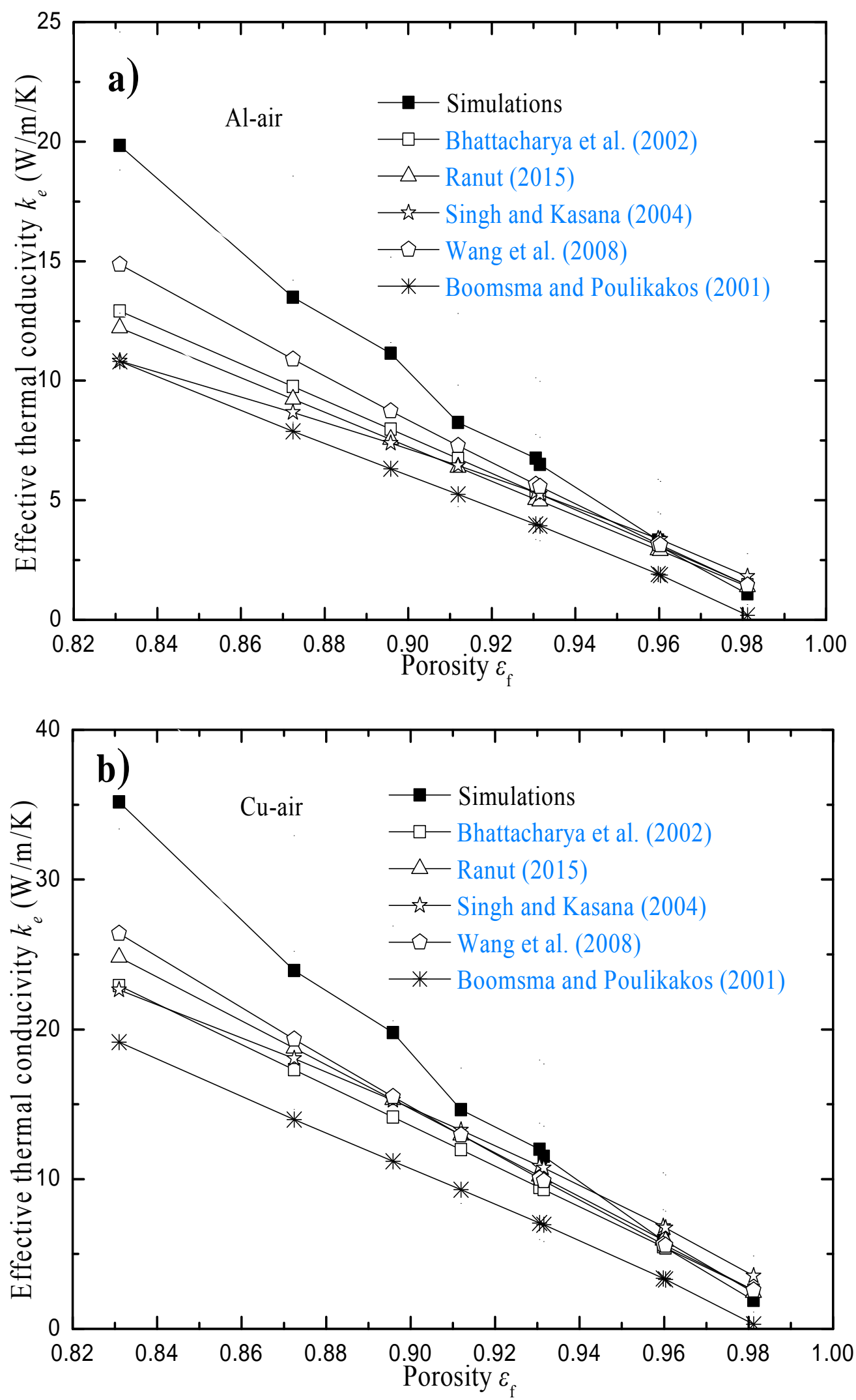

Fig. 6. Comparisons of the simulated effective thermal conductivity of coated foams with the conductivity of washcoat equal to that of metal support with the predicted values by some typical correlations for metal foams. a) Aluminia-air; b) Copper-air. 

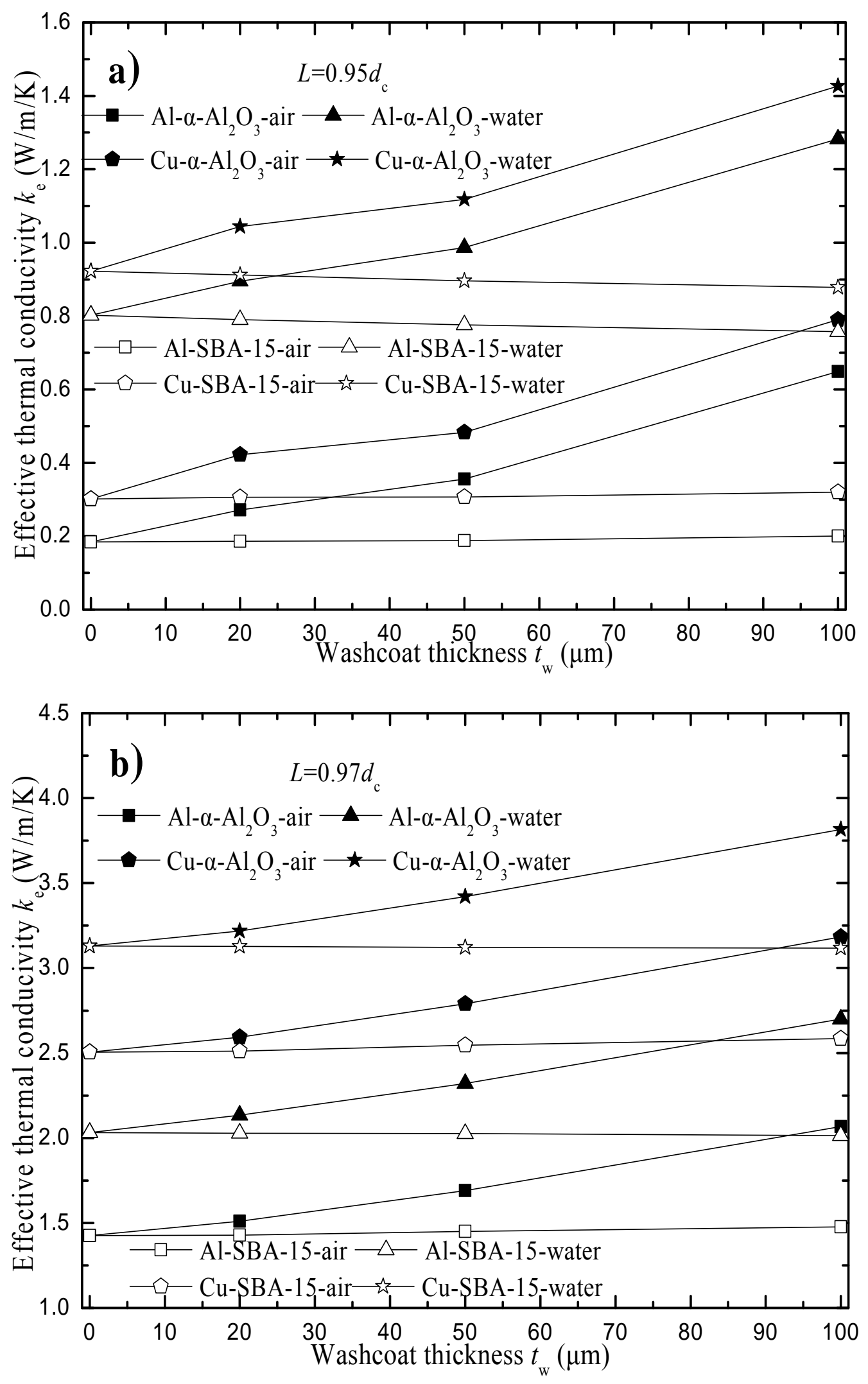


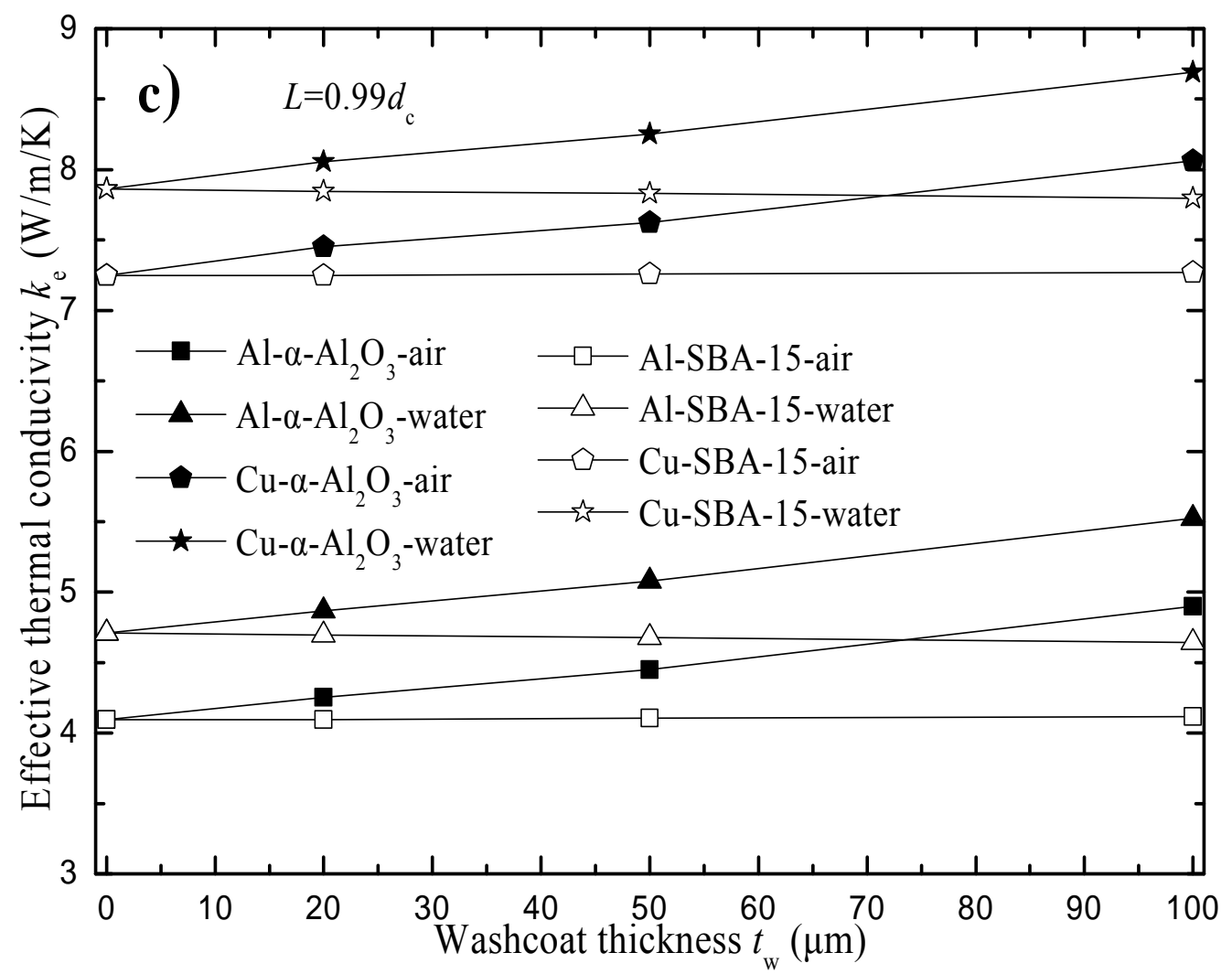

Fig. 7. The effective thermal conductivity of coated metal foams with the varying thickness of washcoat. a) $L=0.95 d_{\mathrm{c}}$; b) $L=0.97 d_{\mathrm{c}}$; c) $L=0.95 d_{\mathrm{c}}$.

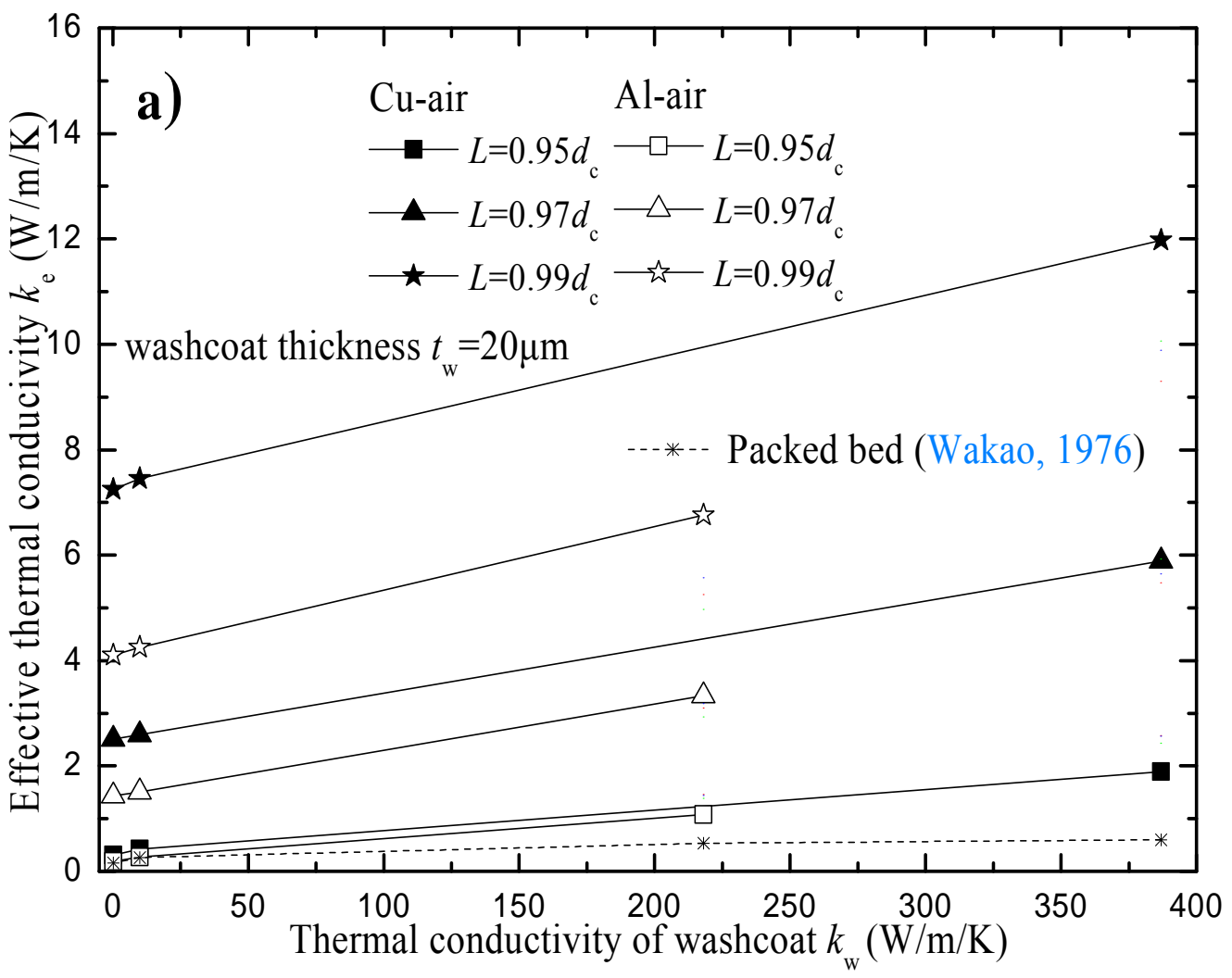



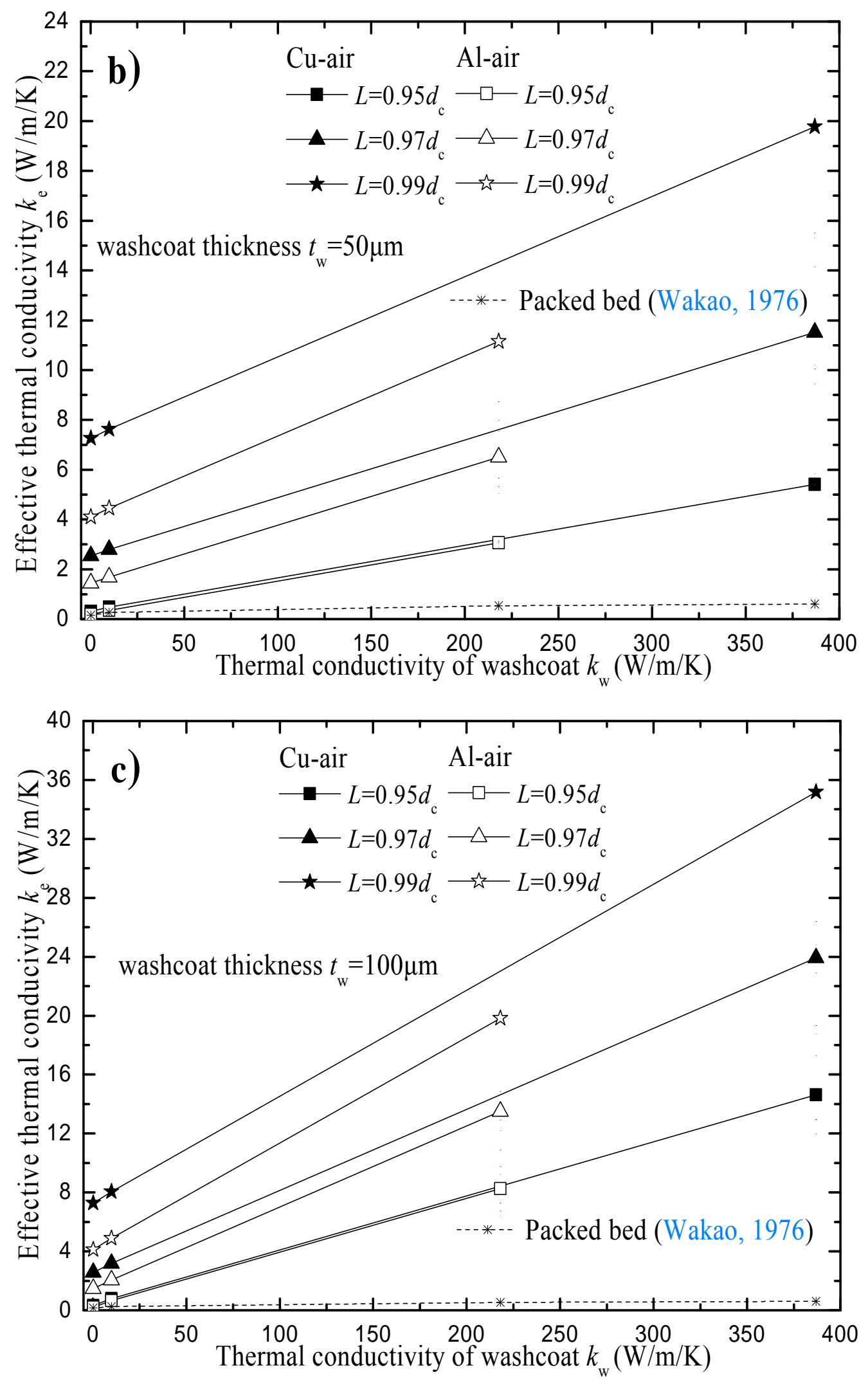

Fig. 8. The effective thermal conductivity of coated metal foams with the varying conductivity of washcoat. a) $t_{\mathrm{w}}=20 \mu \mathrm{m}$; $\mathrm{b}$ ) $\left.t_{\mathrm{w}}=50 \mu \mathrm{m} ; \mathrm{c}\right) t_{\mathrm{w}}=100 \mu \mathrm{m}$ 


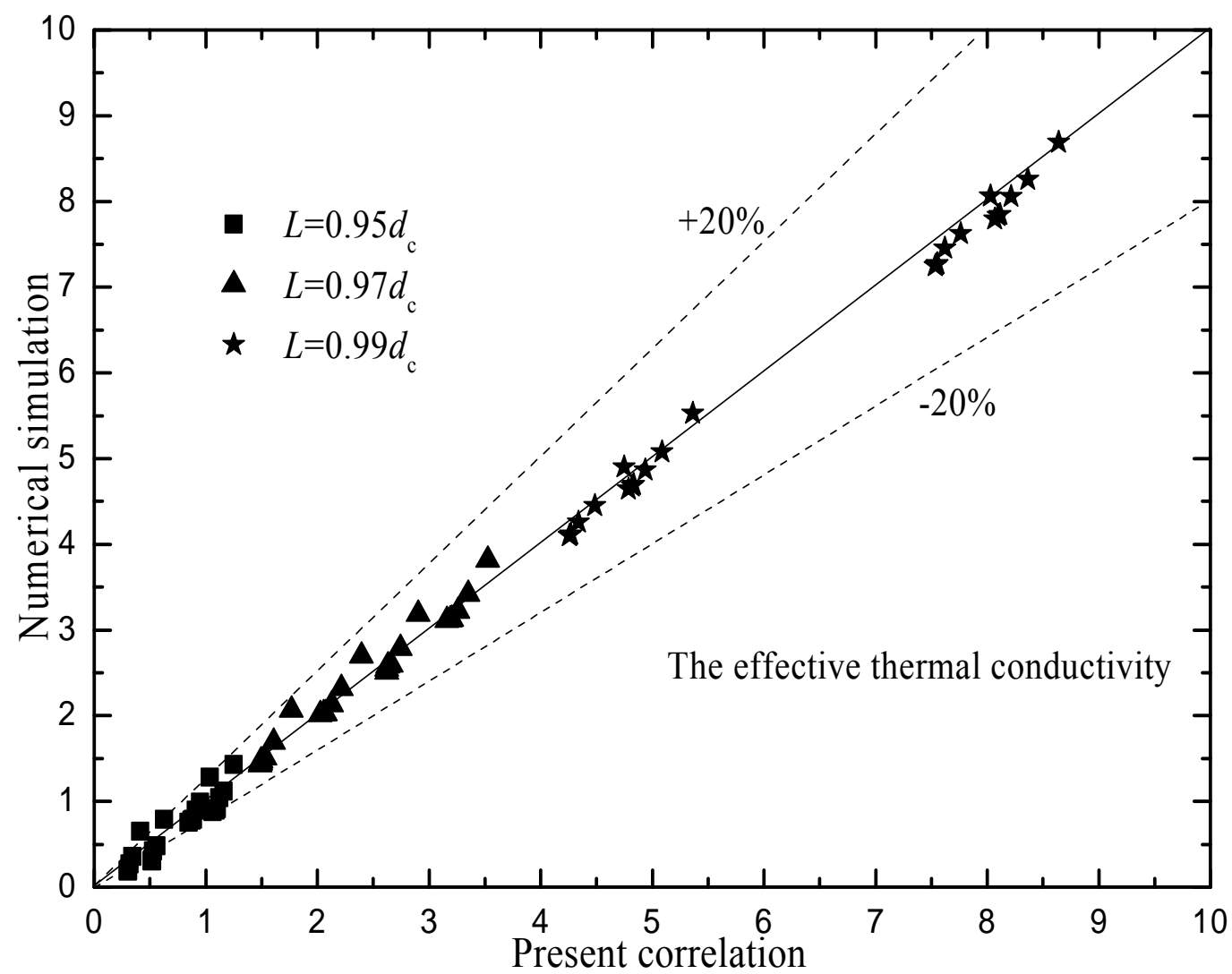

Fig. 9. Comparisons of the predicted effective thermal conductivity by the present correlation and the simulated ones.

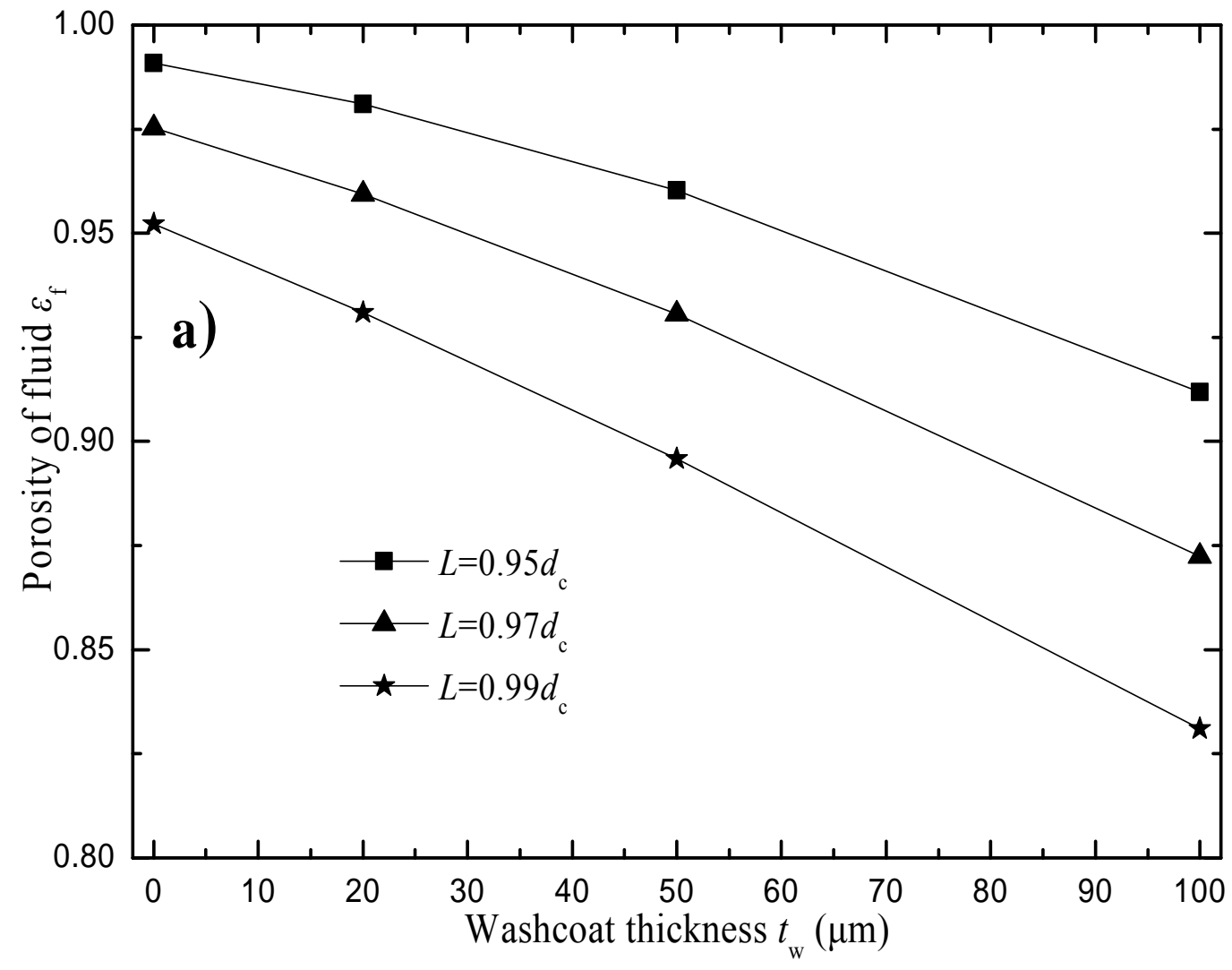



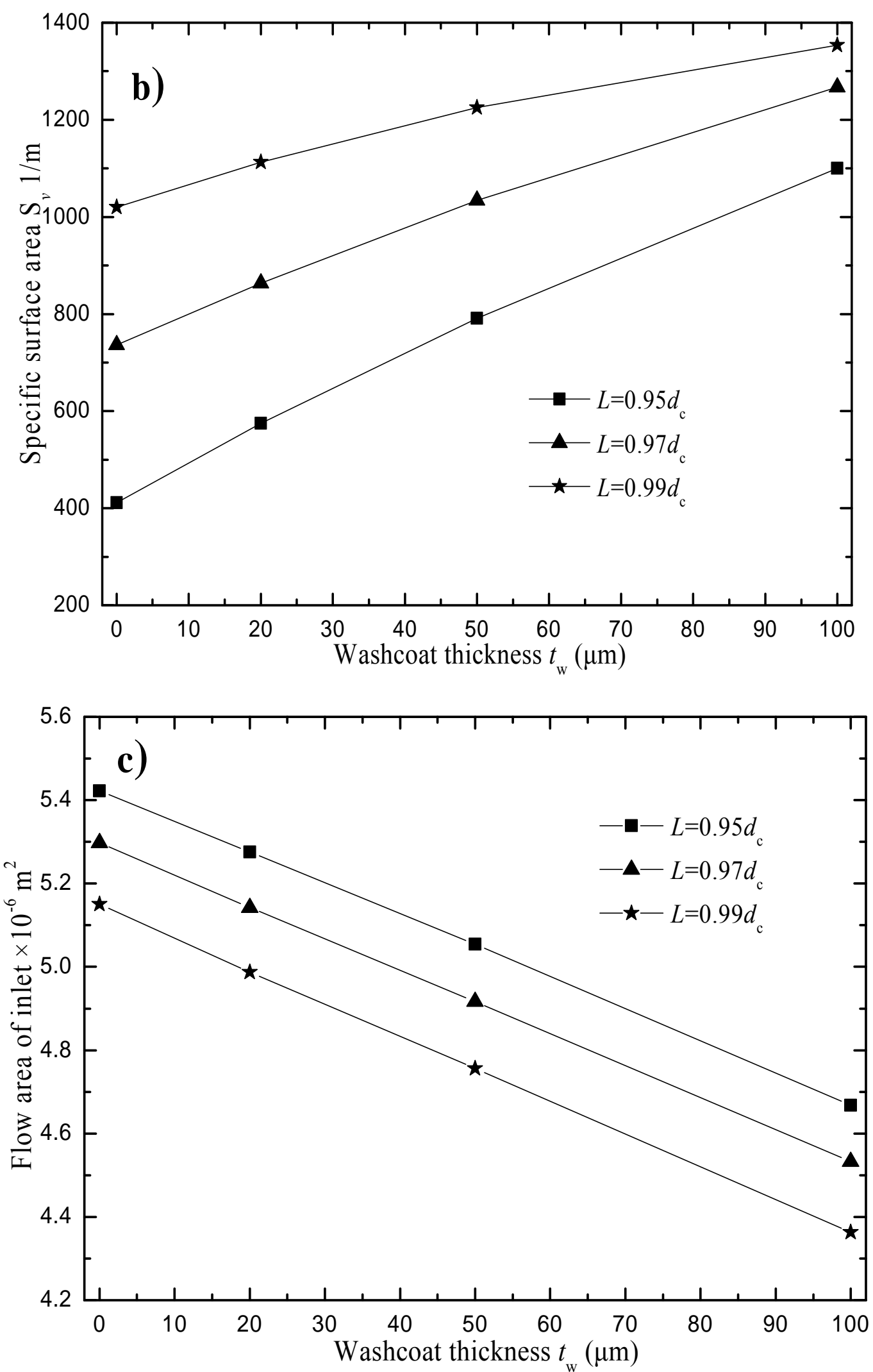

Fig. 10. Structural parameters of coated metal foams as a function of the washcoat thickness. a) Porosity; b) Specific surface area; c) Flow area of inlet. 

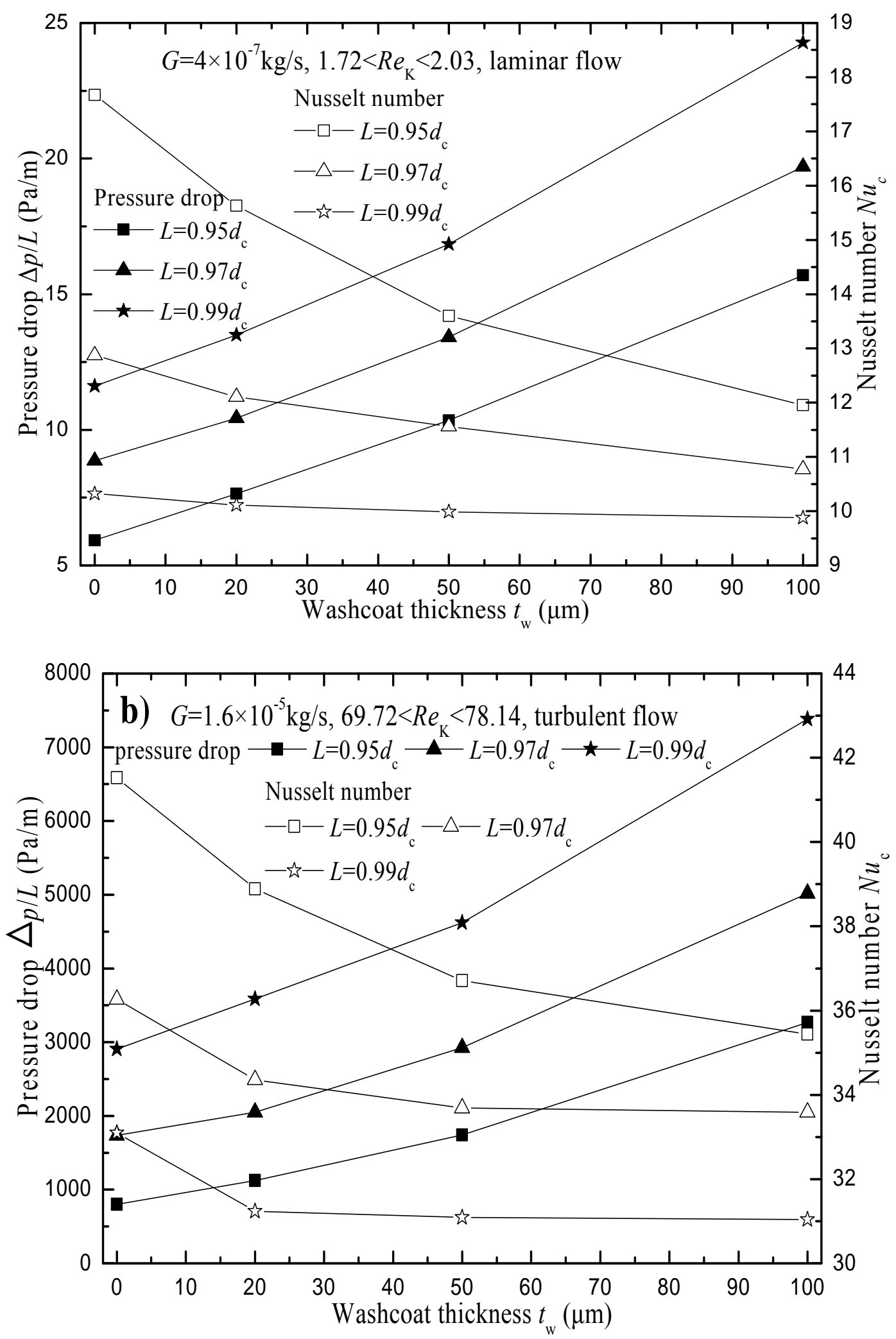

Fig. 11. Pressure drop and Nusselt number as a function of the washcoat thickness. a) Laminar flow and b) Turbulent flow. 

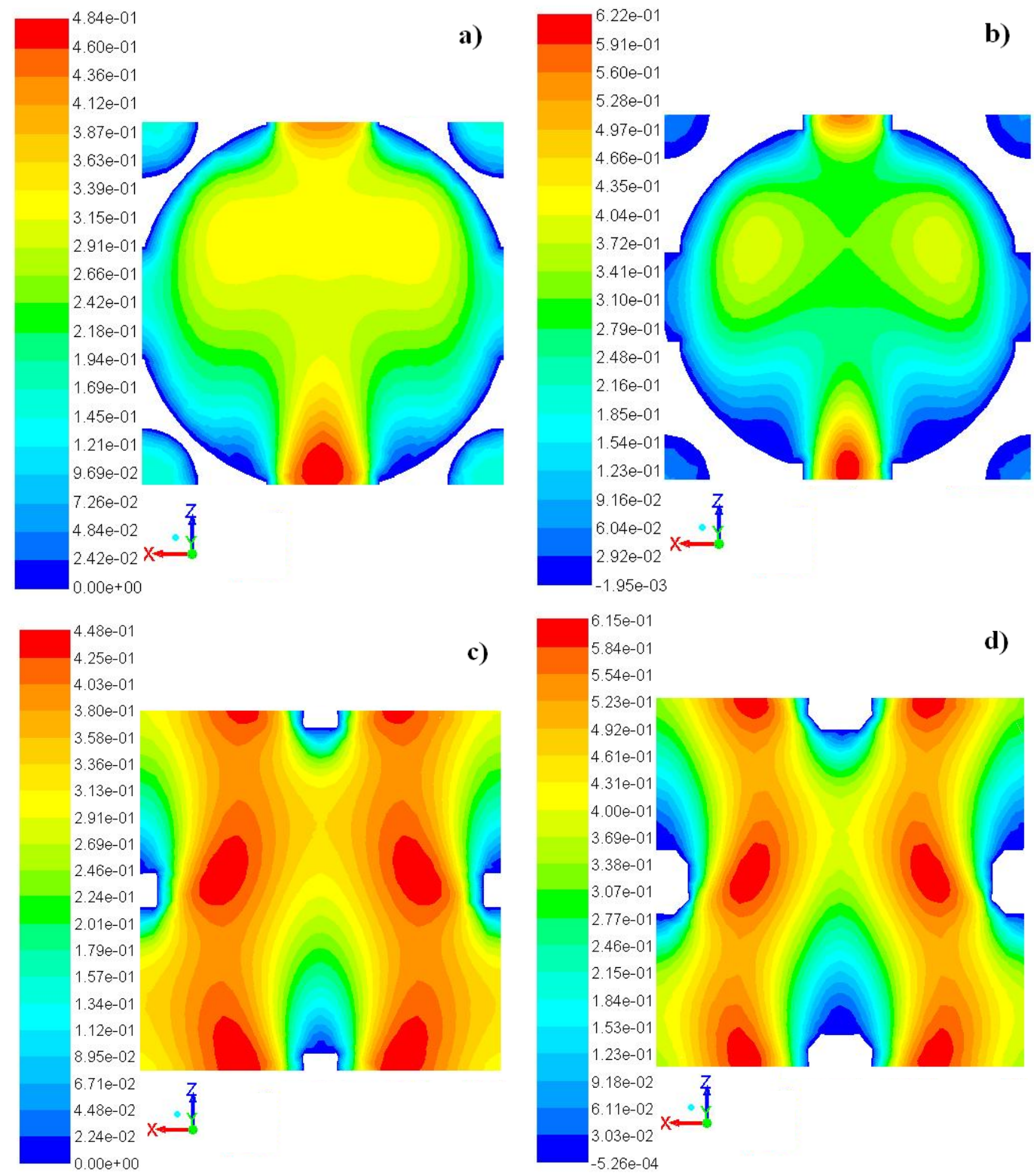

e)

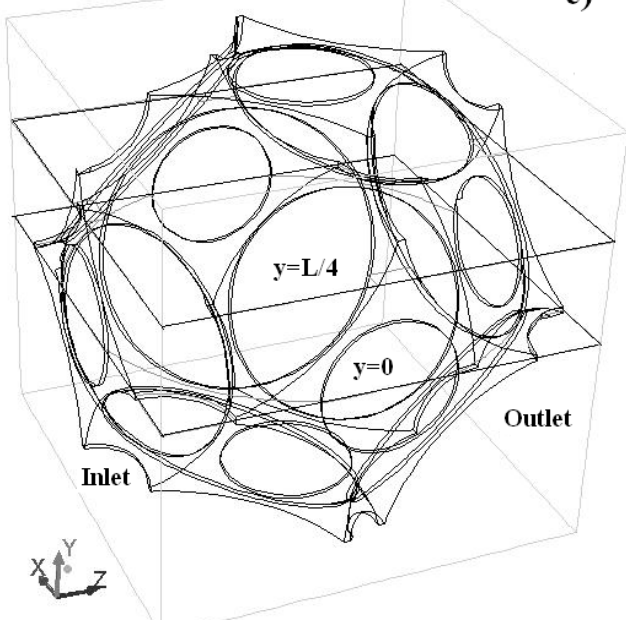

Fig. 12. Nephograms of velocity in the planes of $y=0$ and $y=L / 4$ for metal foams with the washcoat thickness of $20 \mu \mathrm{m}$ and $100 \mu \mathrm{m}$. a) $t_{\mathrm{w}}=20 \mu \mathrm{m}, y=0$; b) $t_{\mathrm{w}}=100 \mu \mathrm{m}, y=0$; c) $t_{\mathrm{w}}=20 \mu \mathrm{m}, y=L / 4$; d) $t_{\mathrm{w}}=100 \mu \mathrm{m}, y=L / 4$; e) The positions of planes of $y=0$ and $y=L / 4$ in unit cell. 

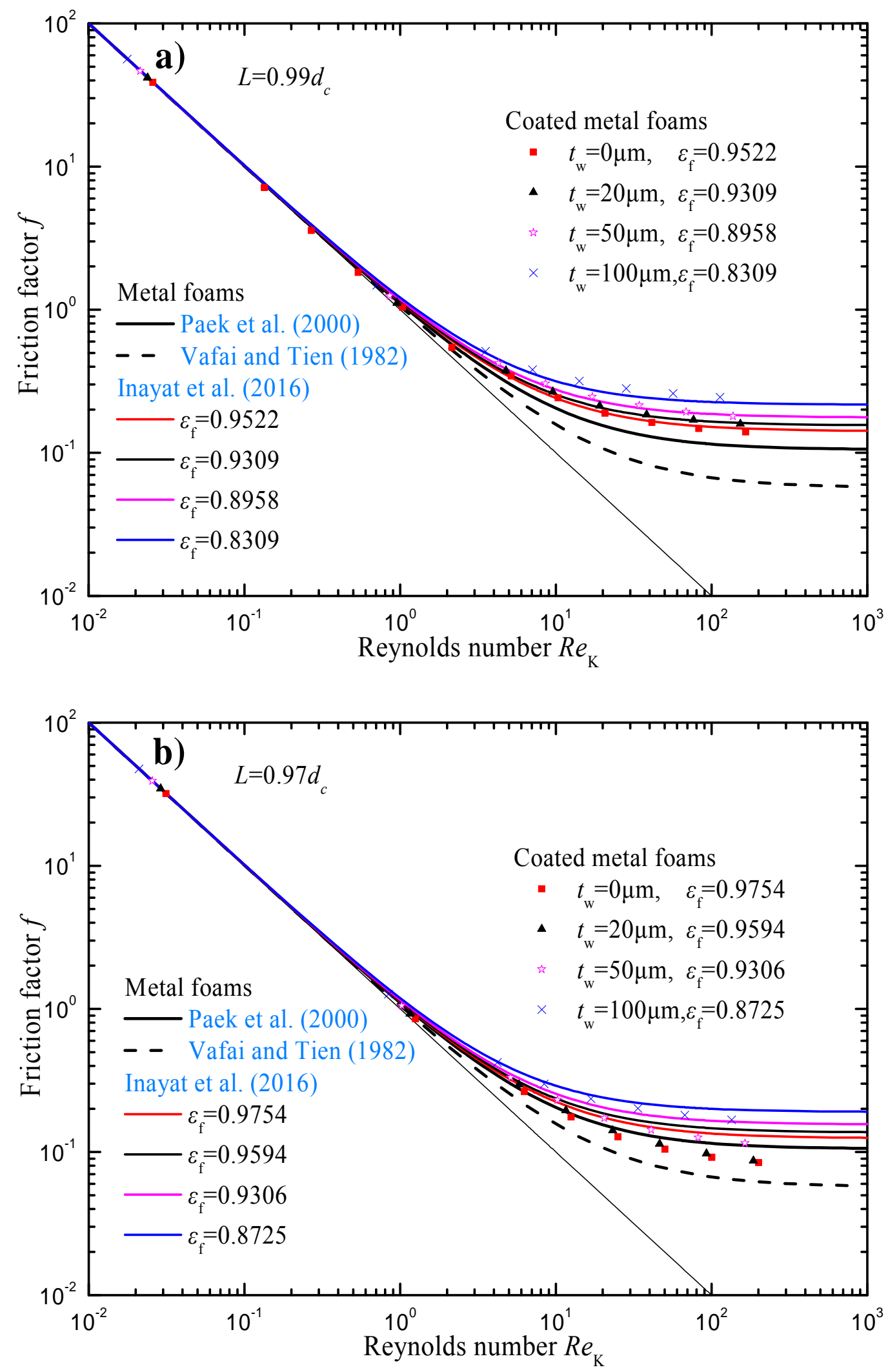


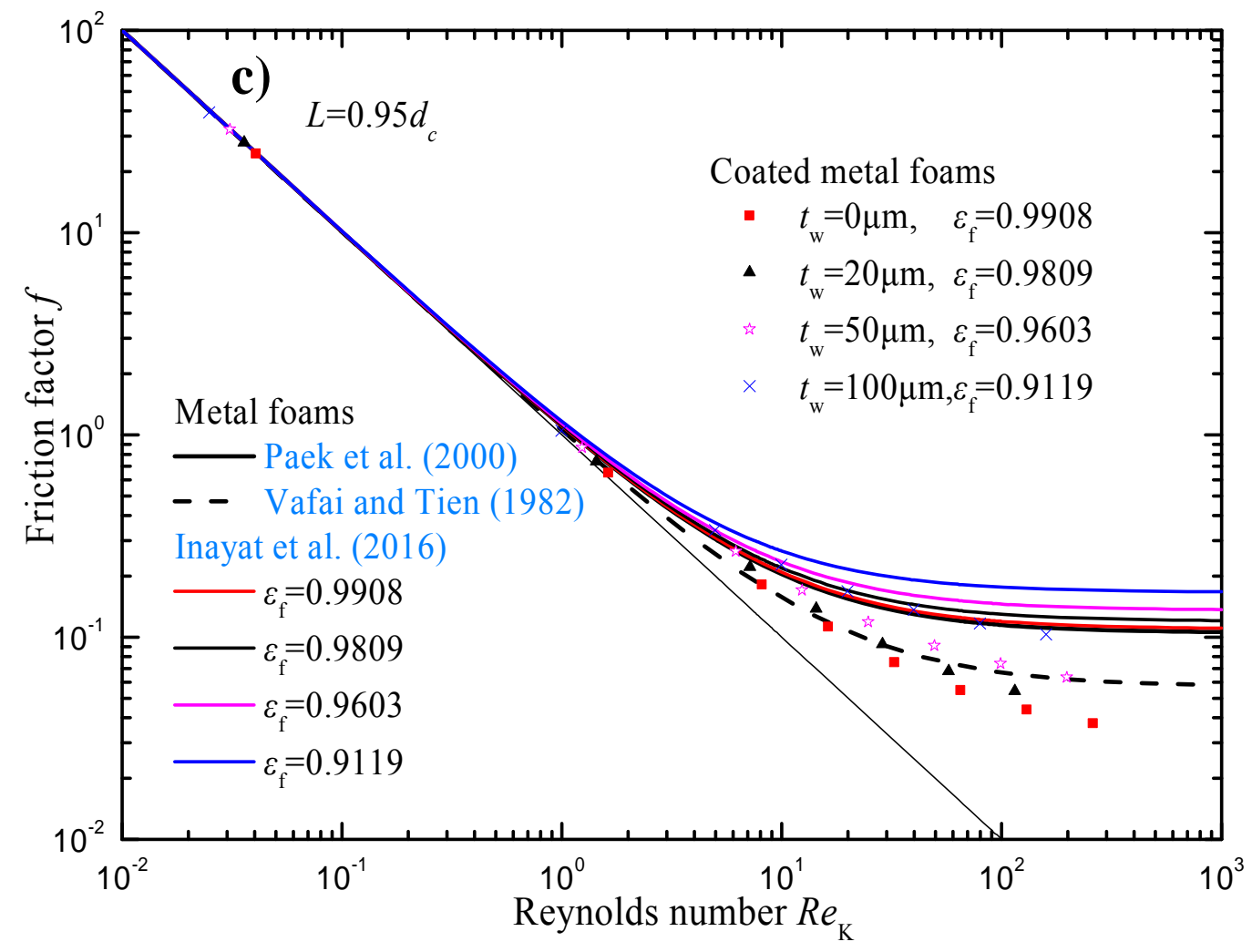

Fig. 13. The hydrodynamic characteristic of coated metal foams. a) $L / d_{\mathrm{c}}=0.99$; b) $L / d_{\mathrm{c}}=0.97$; c) $L / d_{\mathrm{c}}=0.95$.

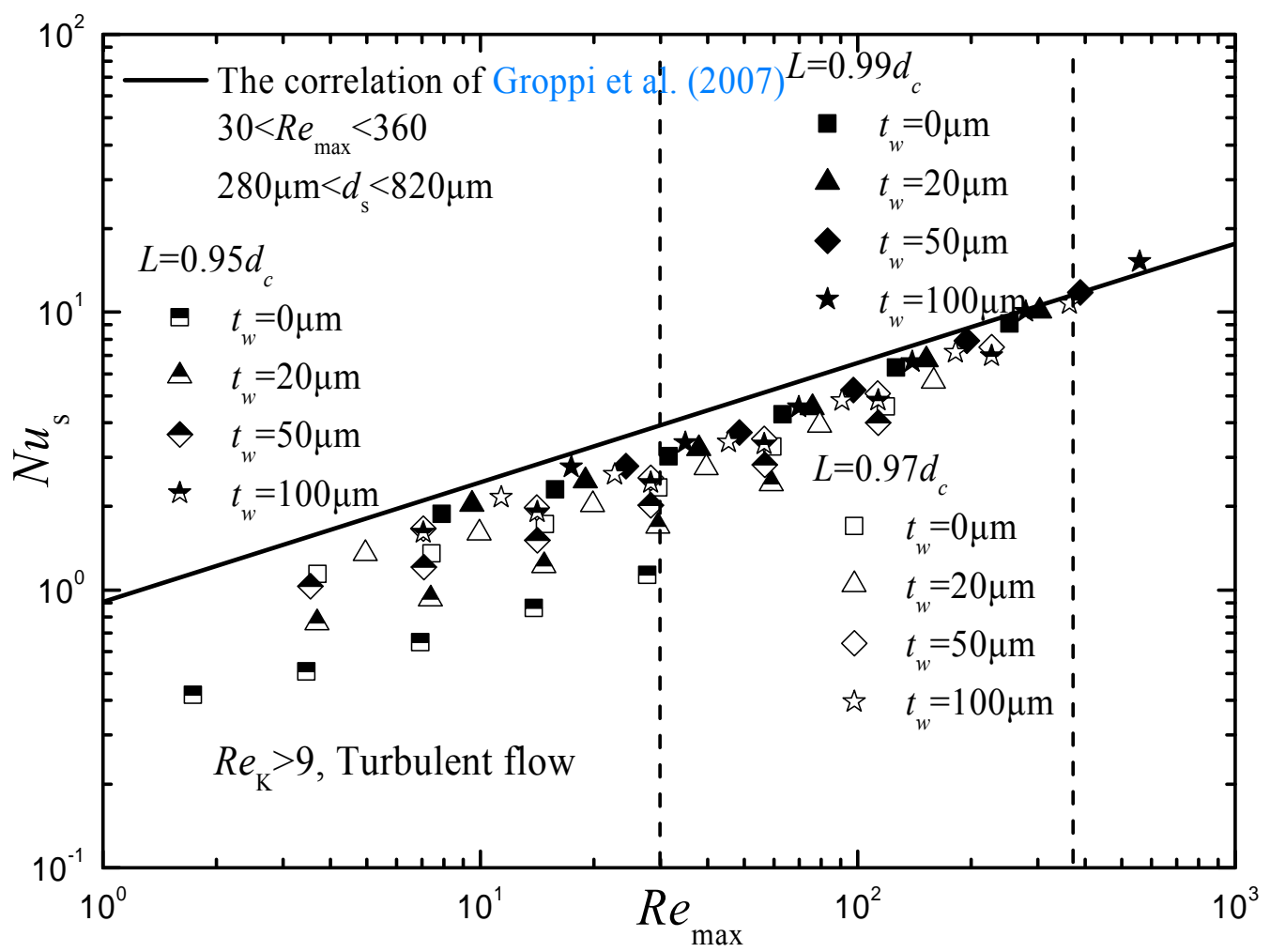

Fig. 14. The interface heat transfer characterstic of coated metal foams in turbulent (The two dash lines respectively represent the low and up limits of $R e_{\max }$ for Groppi et al.'s correlation). 

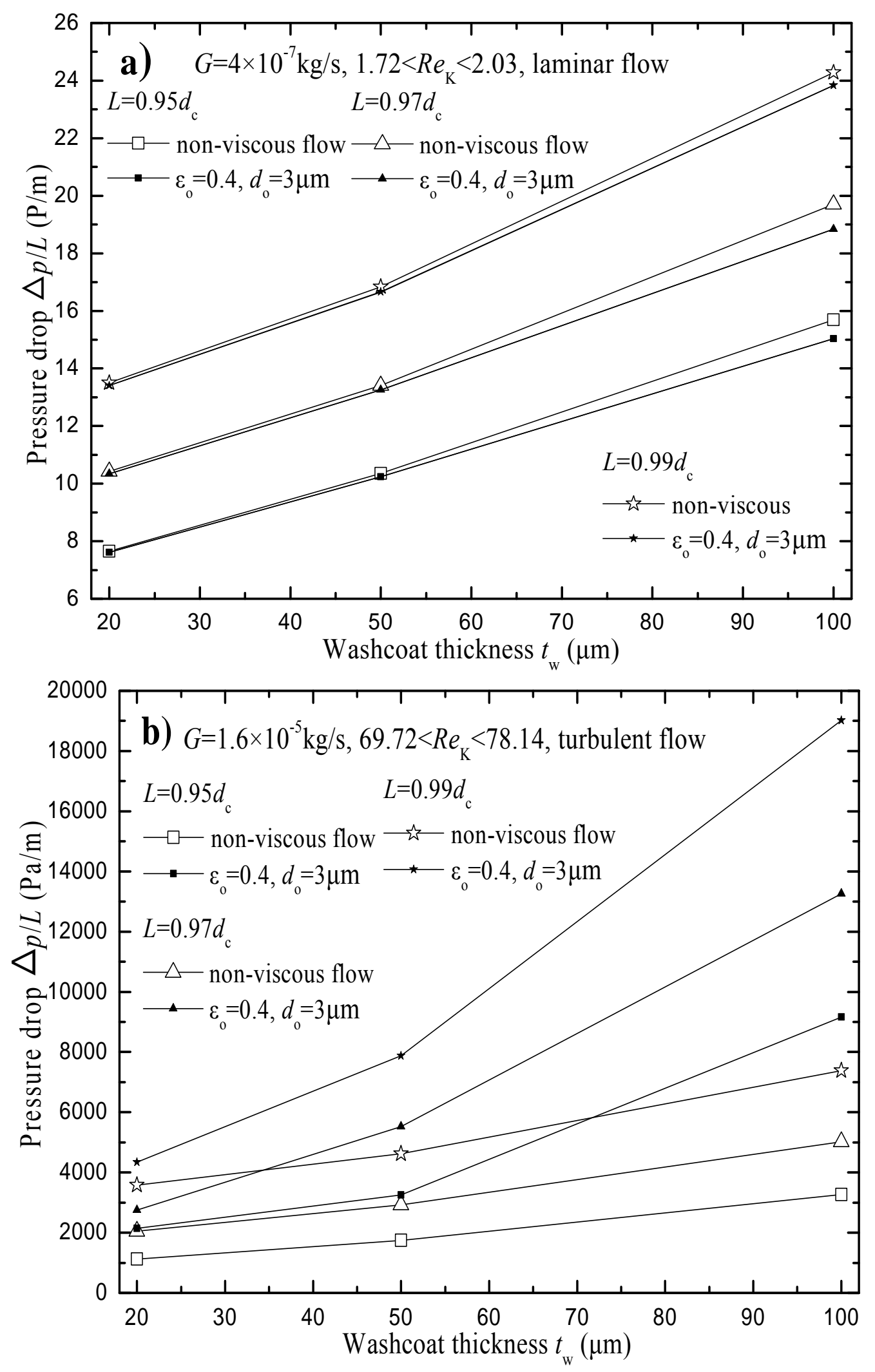

Fig. 15. Comparisons of pressure drop for coated metal foams with and without viscous flow in washcoat. a) $G=4 \times 10^{-7} \mathrm{~kg} / \mathrm{s}$, laminar flow; b) $G=1.6 \times 10^{-5} \mathrm{~kg} / \mathrm{s}$, turbulent flow. 

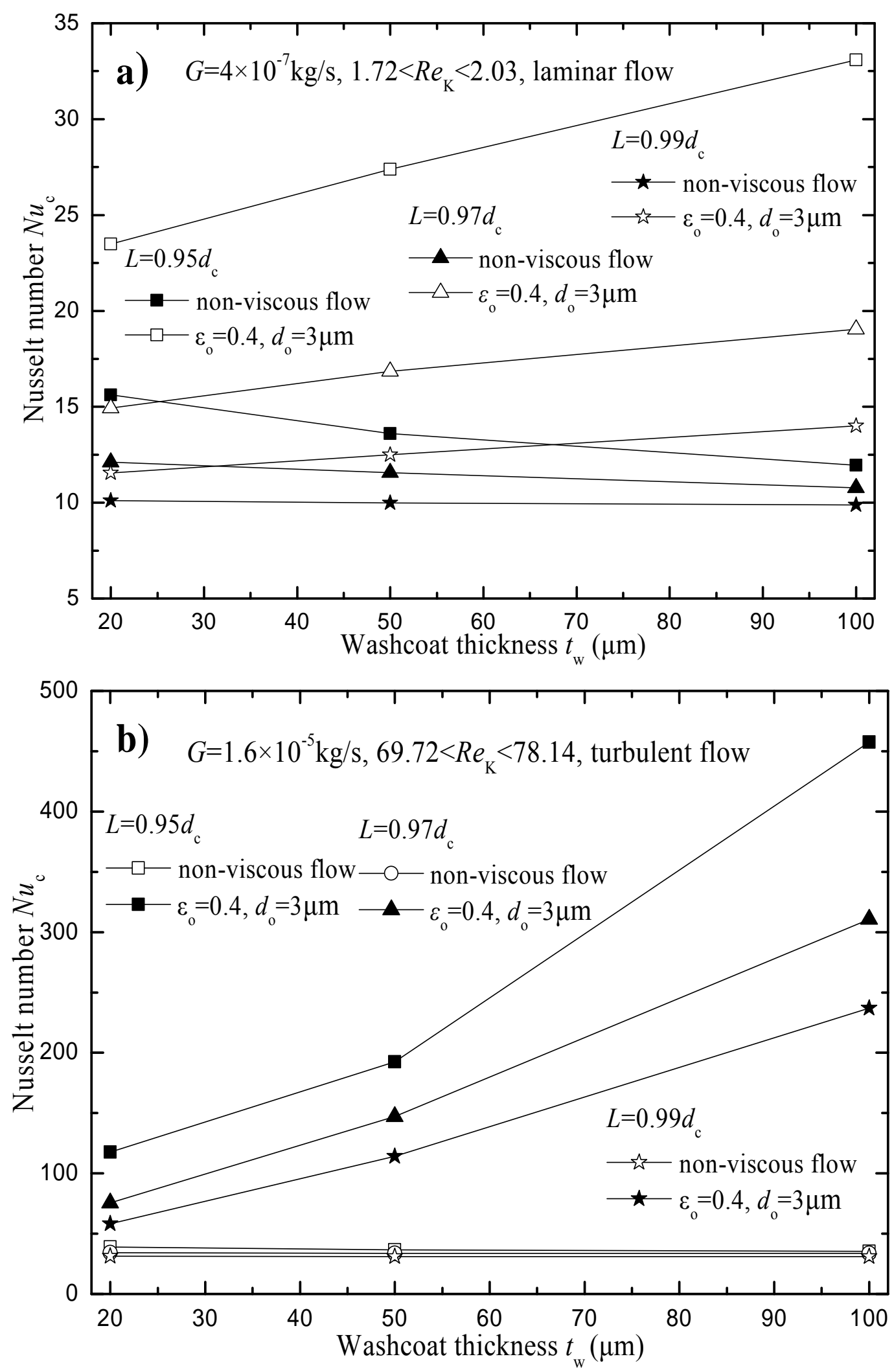

Fig. 16. Comparisons of the Nusselt number for coated metal foams with and without viscous flow in washcoat. a) $G=4 \times$ $10^{-7} \mathrm{~kg} / \mathrm{s}$, laminar flow; b) $G=1.6 \times 10^{-5} \mathrm{~kg} / \mathrm{s}$, turbulent flow. 


\section{Table Captions}

Table 1 The structural parameters of the unit cell (coated metal foams) chosen.

Table 2 The physical property parameters of metal foam support, washcoat and fluid.

Table 3 The correlations of effective thermal conductivity for high porosity open-cell metal foams. 
Table 1 The structural parameters of the unit cell (coated metal foams) chosen.

\begin{tabular}{|c|c|c|c|c|c|}
\hline $\begin{array}{l}\text { Unit cell size } \\
\qquad L(\mathrm{~mm})\end{array}$ & $\begin{array}{l}\text { Mean strut diameter } \\
\qquad d_{\mathrm{s}}(\mu \mathrm{m})\end{array}$ & $\begin{array}{l}\text { Washcoat thickness } \\
\qquad t_{\mathrm{w}}(\mu \mathrm{m})\end{array}$ & $\varepsilon_{\mathrm{s}}(\times 100)$ & $\varepsilon_{\mathrm{w}}(\times 100)$ & $\varepsilon_{\mathrm{f}}(\times 100)$ \\
\hline \multirow{3}{*}{0.95} & \multirow{3}{*}{39.6913} & 20 & 0.9174 & 0.9839 & 98.0987 \\
\hline & & 50 & 0.9175 & 3.0495 & 96.0329 \\
\hline & & 100 & 0.9176 & 7.8914 & 91.1910 \\
\hline \multirow{3}{*}{0.97} & \multirow{3}{*}{163.426} & 20 & 2.4639 & 1.6010 & 95.9351 \\
\hline & & 50 & 2.4653 & 4.4716 & 93.0631 \\
\hline & & 100 & 2.4650 & 10.2883 & 87.2467 \\
\hline \multirow{3}{*}{0.99} & \multirow{3}{*}{328.935} & 20 & 4.7775 & 2.1300 & 93.0925 \\
\hline & & 50 & 4.7789 & 5.6380 & 89.5831 \\
\hline & & 100 & 4.7787 & 12.1234 & 83.0978 \\
\hline
\end{tabular}

Table 2 The physical property parameters of metal foam support, washcoat and fluid.

\begin{tabular}{cccccc}
\hline Material & Zone & $\begin{array}{c}\text { Density } \\
\left(\mathrm{kg} / \mathrm{m}^{3}\right)\end{array}$ & $\begin{array}{c}\text { Heat capacity } \\
(\mathrm{J} / \mathrm{kg} / \mathrm{K})\end{array}$ & $\begin{array}{c}\text { Conductivity } \\
(\mathrm{W} / \mathrm{m} / \mathrm{K})\end{array}$ & $\begin{array}{c}\text { Dynamic viscosity } \\
(\text { Pas })\end{array}$ \\
\hline $\mathrm{Al}$ & Support zone & 2710 & 902 & 218 & - \\
$\mathrm{Cu}$ & Support zone & 8978 & 381 & 387 & - \\
$\alpha-\mathrm{Al}_{2} \mathrm{O}_{3}$ & Washcoat zone & 3900 & 499 & 10 & - \\
$\mathrm{SBA}-15$ & Washcoat zone & 350 & 499 & 0.3 & - \\
air & Fluid zone & 1.225 & 1006.43 & 0.0265 & $1.78 \times 10^{-5}$ \\
water & Fluid zone & 995.7 & 4174 & 0.613 & - \\
\hline
\end{tabular}

Table 3 The correlations of effective thermal conductivity for high porosity open-cell metal foams.

\begin{tabular}{lcl}
\hline \multicolumn{1}{c}{ Authors } & Correlations & \multicolumn{1}{c}{ Parameters } \\
\hline Bhattacharya et al. (2002) & $k_{\mathrm{e}}=F k_{\mathrm{II}}+(1-F) k_{\perp}$ & $\begin{array}{l}F=0.35 \text { for aluminum foams } \\
F=0.331 \text { for aluminum-air, } F=0.379 \text { for aluminum-water } \\
\text { Ranut (2015) }\end{array}$ \\
Singh and Kasana (2004) & $k_{\mathrm{e}}=k_{\mathrm{II}}^{F} k_{\perp}^{1-F}$ & $\begin{array}{l}F=\mathrm{C}\left[0.3031+0.0623 \ln \left(\varepsilon_{\mathrm{f}} \mathrm{k}_{\mathrm{s}} / \mathrm{k}_{\mathrm{f}}\right)\right], \mathrm{C}=0.9683 \text { for aluminum-air, } \\
\mathrm{C}=1.0647 \text { for aluminum-water }\end{array}$ \\
Wang et al. (2008) & $k_{\mathrm{e}}=k_{\mathrm{s}}\left[0.5-\cos \left(\frac{\pi+\arccos \left(1-2\left(1-\varepsilon_{\mathrm{f}}\right)\right)}{3}\right)\right]^{2}$ for metal foams \\
Boomsma and Poulikakos & $k_{\mathrm{e}}=\left[\sqrt{2}\left(R_{A}+R_{B}+R_{C}+R_{D}\right)\right]^{-1}$ for metal foams, $R_{A}, R_{B}, R_{C}, R_{D}$ refers to the \\
(2001) & literature
\end{tabular}

